\title{
MaSs Torts AND THE INCENTIVES FOR SUIT, SETTLEMENT, AND TRIAL by
}

Andrew F. Daughety and Jennifer F. Reinganum

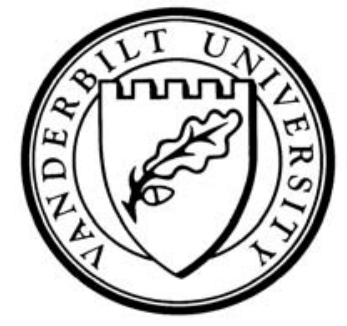

Working Paper No. 07-W13

August 2007

\section{DEPARTMENT OF ECONOMICS \\ VANDERBILT UNIVERSITY \\ NASHVILLE, TN 37235}

www.vanderbilt.edu/econ 
Mass Torts and the Incentives for Suit, Settlement, and Trial*

\author{
Andrew F. Daughety \\ Jennifer F. Reinganum \\ Department of Economics \\ and Law School \\ Vanderbilt University \\ Nashville, TN 37235 \\ andrew.f.daughety@vanderbilt.edu \\ jennifer.f.reinganum@vanderbilt.edu
}

August 2007

* We thank John Goldberg, Richard Nagareda, Richard Posner, Chris Sanchirico, and Steve Shavell for helpful suggestions. 


\title{
Mass Torts and the Incentives for Suit, Settlement, and Trial
}

\author{
Andrew F. Daughety \\ Jennifer F. Reinganum
}

\begin{abstract}
We explore how the incentives of a plaintiff and her attorney, when considering filing suit and bargaining over settlement, can differ between those suits associated with stand-alone torts cases and those suits involving mass torts. We contrast "individual-based liability determination" (IBLD), wherein a clear description of the mechanism by which a defendant's actions translate into a plaintiff's harm is available, with "population-based liability determination" (PBLD), wherein cases rely upon the prevalence of harms in the population to persuade a judge or jury to draw an inference of causation or fault. We show that PBLD creates a positive externality for the plaintiff's side that is inherent in many mass tort settings; this externality induces an increased propensity to file suit, higher settlement demands and greater joint payoffs for plaintiffs and their attorneys. Consequently, the defendant in a PBLD case faces an increased ex ante expected cost compared with the IBLD regime, thereby increasing incentives to take care. However, PBLD need not always imply an increased likelihood of trial relative to IBLD for any filed case (though it may lead to more cases being filed); the heightened aggressiveness of the plaintiff and her attorney can actually lead to a reduction in the likelihood of trial. Thus, PBLD can be more, or less, efficient than IBLD (in the sense of reducing trial costs), when considering cases that would be filed in both possible regimes.
\end{abstract}

Keywords: liability determination, settlement bargaining

JEL Codes: K13, K41, D82 


\section{Introduction}

In this paper we explore how the incentives of a plaintiff and her attorney, when considering filing suit and bargaining over settlement, can differ between those suits associated with stand-alone torts cases and those suits involving mass torts (e.g., harms from broadly-marketed pharmaceuticals ${ }^{1}$ ). We show that there is a positive externality for the plaintiff's side that is inherent in many mass tort settings; this externality induces a higher settlement demand and a greater joint payoff for the plaintiff and her attorney. Moreover, the increased (rational) aggressiveness that the externality induces in the plaintiff's side results in incentives to bring a suit that would otherwise fail to be brought, and stronger incentives for the defendant to take care, but may actually lead to a lower likelihood of trial.

We view typical liability determination as reflecting a mix of "individual-based liability determination" (hereafter: IBLD) and "population-based liability determination” (hereafter: PBLD). IBLD reflects individual-based assessments of the defendant and his actions; here we are including circumstances wherein a clear description of the mechanism by which a defendant's actions translate into a plaintiff's harm is available. PBLD reflects population-based assessments that suggest that a defendant should be held liable for a harm. Such cases rely upon the prevalence of harms in the population to persuade a judge or jury to draw an inference of causation (or fault). In these cases, no mechanism of direct cause is explicitly stated, often because the relevant science cannot reliably list the exact sequence of events and decisions that link an initial action to an eventual harm.

It is the second basis for determining liability (PBLD) that is frequently at the heart of many mass torts; evidence of this is seen in the recurring "battle of the statistical experts" which occurs

1 In Section 2 of the paper we go into more detail on a number of examples. 
in such cases (see the Reference Manual on Scientific Evidence, 2000) ${ }^{2}$. For instance, epidemiological evidence regarding causation has figured prominently in products liability actions involving, for example, the anti-nausea drug Bendectin, the swine flu vaccine, radiation exposure, exposure to dioxin (Agent Orange), and smoking. ${ }^{3}$ It seems likely that such evidence will figure prominently in on-going litigation involving the diet drug cocktail fen-phen and the pain-reliever Vioxx. In Section 2 we discuss some examples in more detail (considering both causation and fault) and contrast them with more classic IBLD cases. These two bases for liability determination ${ }^{4}$ influence findings of causation, and sometimes (under negligence) of fault, and can differentially affect a plaintiff's-side assessment of the likely outcome of undertaking a suit.

\section{The Research Strategy Used in This Paper}

Our objective is to analyze the direction (and, to the degree possible, the magnitude) of the effect of using PBLD on the economic incentives for potential plaintiffs and potential defendants (e.g., incentives to file, settlement demands, and incentives for care) in the case of mass-marketed products or situations of mass harms. Our comparison point is the same bundle of economic incentives under IBLD. This is a complex subject, and the purpose of any analysis is to try to

2 This manual is published by the Federal Judicial Center as an aid to judges to help them understand and vet scientific evidence submitted in court.

3 See Green, et. al. (2000, p. 335, footnote 5) for case citations; this is one of a collection of articles in the Reference Manual on Scientific Evidence (2000). Note that not all these cases have resulted in decisions for the plaintiffs.

4 Our analysis will employ a "proportional liability" model in contrast with a "threshold liability" model that generates a binary decision of liable/not-liable (see Shavell, 1987, for a discussion distinguishing these two approaches). The use of a proportional liability model is fairly standard practice in settlement analyses, especially since we abstract from the process by which evidence is mapped into a verdict. For an analysis using evidence to achieve a proportional assessment, which then leads to a threshold decision, see Daughety and Reinganum (2000a). 
characterize the primary forces at work.

In order to accomplish this we will do three things to sharpen the analysis. First, while we will identify the differential incentive for a potential defendant to take care, tracing that back to the equilibrium care level must wait for another paper. Second, some mass torts are addressed via (successfully-certified) class action suits, but some proceed on a more disaggregated basis. ${ }^{5}$ We abstract from this issue in our model, but return to discuss it briefly in Section 7 . There we indicate that the externality in liability determination that we identify in this paper is likely to be one important driver of class formation (completely separable from, but possibly enhancing, any cost saving due to scale economies), so understanding the incentive effects of different types of liability determination is important, whether the context is an individual or a class action suit. In short, we expect that class actions will simply magnify the results we find in this paper.

Third, we simplify the analytical modeling of PBLD by relating it to the fraction of people harmed (in a variety of ways, as shown in Sections 4 and 6 and in the Appendix). This last assumption is essential to understand; a nice example might be the epidemiological analysis used to prove causation that is involved in mass torts arising from a new drug that is marketed. Drugs are tested before the FDA approves them for general distribution; after approval, the general distribution of the drug constitutes a large-scale test, frequently with millions of subjects. Lawsuits over harms arising in this post-approval environment may have access to all the earlier testing results, but plaintiffs contemplating filing a suit generally do not have access to what is happening

5 Plaintiffs proceed individually or in smaller classes for a variety of reasons: their situations may be sufficiently diverse as to preclude class certification, some may opt out of a class, and so on. We return to this issue, and how our analysis in this paper may contribute to an extension that incorporates class action considerations, in Section 7. For a model of class formation, see Che (1996, 2002). 
post-approval, and much of that will only come out in a combination of (typically) lengthy discovery and, if settlement fails, trial.

Since a potential plaintiff and her attorney must contemplate whether or not to file suit, anticipating the likely outcome of a bargaining process and the possibility of trial, they must forecast the likelihood of the defendant being found liable by using the past information about the preapproval drug tests and any information gleaned from more recent, evolving drug research. This latter aspect is difficult to capture in a form that is manipulable. Here is where the third strategy described earlier comes in: if a primary driver of PBLD is the fraction of users harmed (and we'll make this case at various points in the paper), then predicting this fraction via combining the preapproval characterization of the likelihood of liability with the post-approval experience of being harmed (as the simplest version of what information the plaintiff and her lawyer can accumulate when considering their litigation strategy) is a job for Bayes' Rule. We provide a stark example of this below and use the general principle in our analysis from Section 4 on.

\section{An Illustration of the Positive Externality in PBLD}

To see the basic source of this positive externality, assume that a product is purchased by 1000 buyers and that either 10 or 50 buyers will be harmed, with equal likelihood; that is, either $1 \%$ or $5 \%$ of the population "exposed" to the product will be harmed, each with probability $1 / 2$. We assume that every individual in the overall population of the 1000 buyers is equally likely to be among those harmed; no individual has a predisposition for being harmed. Thus, if 10 people are harmed, any individual buyer has a 1\%-chance of being harmed; call this probability $\mathrm{A}$, so $\mathrm{A}=$ $\operatorname{Pr}\{$ an individual is harmed $\mid$ harm rate $=1 \%\}=0.01$. Similarly, if 50 people are harmed, any individual buyer has a 5\%-chance of being harmed; call this probability $\mathrm{B}$, so $\mathrm{B}=\operatorname{Pr}\{$ an individual 
is harmed $\mid$ harm rate $=5 \%\}=0.05$. These probabilities represent ex ante information.

Assume that the victim and her attorney know the foregoing information and are considering the value of a suit against the defendant. Further assume that the likelihood that the defendant will be found liable is increasing in the fraction of the buyers who are harmed. When the victim and her attorney consider her situation, she has already been harmed, so they now view this issue from an ex post position and ask which group is more likely to have occurred (since this affects their expected payoff from filing the suit). ${ }^{6}$ Thus, they wish to compute the probability that the harm rate is $\mathrm{x}$ (where $\mathrm{x}$ is either $1 \%$ or $5 \%$ ) given that the victim has been harmed. As rational bargainers they would use Bayes' Rule to update the likelihood of the rate of harm (note, since A and B are each multiplied by the prior probability of $1 / 2$, we cancel these halves out in what follows for readability):

$$
\begin{aligned}
& \operatorname{Pr}\{\text { harm rate }=1 \% \mid \text { the victim was harmed }\}=\mathrm{A} /(\mathrm{A}+\mathrm{B})=1 / 6<1 / 2 . \\
& \operatorname{Pr}\{\text { harm rate }=5 \% \mid \text { the victim was harmed }\}=\mathrm{B} /(\mathrm{A}+\mathrm{B})=5 / 6>1 / 2 .
\end{aligned}
$$

That is, while the prior assessments of the rate of harm are $1 / 2$ for each group, the posterior assessments are quite different. This is because there are two groups that the victim could be in: the smaller group of victims or the larger group of victims. Since the victim has been harmed, it is rational for her to place a higher likelihood on the random outcome that she is part of the larger group of victims rather than the random outcome that she is part of the smaller group of victims. Thus, if the value of suing will be influenced by (say) the fraction of the population harmed, the dependence of the plaintiff's side's payoff on the fraction of the population of potential victims who actually were harmed enters its forecast of that fraction via Bayes' Rule. The plaintiff's side will

${ }^{6}$ Deneckere and Peck (1995) and Dana (2001) use this idea, in a different context, to model a consumer's posterior assessment of the size of market demand. 
use the above estimate of $5 / 6$ (and the complementary probability that $\operatorname{Pr}\{$ harm rate $=1 \% \mid$ the victim was harmed $\}=1 / 6$ ) when computing its expected payoff from filing a suit, bargaining over settlement, and possibly going to trial.

Note that the foregoing computation is not the result of a model that posits optimism about the likelihood of winning a suit on the part of the victim. Rather, in the context of (say) a massmarketed product, it is the recognition that harm is likely to have occurred in other cases, and that mass harm can play a role in supporting a finding of liability on the part of a defendant, that leads to a positive externality which redounds to the benefit of the case at hand. The positive externality here is that there is settlement bargaining "in the shadow of other related harms," which creates a form of leverage for the plaintiff's side since it induces a shift of the plaintiff's side's assessment toward higher values of the likelihood of the defendant being found liable. ${ }^{7}$ Furthermore, as all victims individually update in this manner, the potential defendant ends up possibly facing more suits, each involving a more aggressive plaintiff.

\section{Plan of the Paper}

We show that incorporating recognition of this externality in the analysis implies an increased settlement demand, higher ex ante expected joint recovery for the plaintiff and the plaintiff's attorney, an increased propensity to file suit, and higher ex ante expected costs for the defendant. We also show that, for suits that would be filed under an IBLD model of liability determination, incorporating the positive externality may lead to a prediction of fewer trials.

7 Of course, someone who used the product and was not harmed would update her assessment and thereby compute a posterior estimate of the likelihood of the larger group of possible victims having been harmed that was less than the prior of $1 / 2$. However, this does not matter, as unharmed users will not be able to sue since we assume that harm is observable and verifiable. 
In Section 2 we provide examples of cases wherein the two bases of liability determination discussed above (IBLD and PBLD) appear. In Section 3 we provide a "pure" IBLD model of suit, settlement, and trial as a simple extension of the standard screening model. In Section 4 we reformulate the analysis for a "pure" model of a PBLD case; Section 5 contains the comparisons of the incentives created by the two types of liability determination. Section 6 addresses some issues of robustness by considering a signaling-game version of the IBLD and PBLD alternatives, and uses the results of the two types of games (screening and signaling) to characterize the consistent results the models generate. We also show that our results in Sections 4 and 5 readily generalize to more complex relationships between the harm rate and the defendant's likelihood of being found liable. Section 7 provides a summary and a discussion of some further (and broader) implications of our analysis as well as a potential extension of our model of PBLD. Proofs of all propositions, and some details raised by the generalizations discussed in Section 6, are in the Appendix.

2. Examples of Individual-Based and Population-Based Liability Determination

\section{IBLD and PBLD in the Context of Causation}

Examples of IBLD, wherein direct cause is established via an explicit sequence of causes and effects, form some of the "classics" of torts classes and law and economics courses. For example, in the 1921 case In re Polemis, direct cause was established via the chain that the fire that destroyed the steamship Polemis was due to a spark that ignited benzene vapors that had accumulated in the ship's hold; the spark was due to a heavy wooden plank that stevedores (employed by the charterers of the ship) had negligently knocked into the hold while they were 
shifting leaking cases of benzene. ${ }^{8}$ As a second example, in Palsgraf v. Long Island Railroad, even though direct cause was not sufficient to win the day, Mrs. Palsgraf was clearly hurt due to a chain of events leading from actions on the part of the railroad's employees to a set of scales on the railroad platform (where she was standing) falling onto her. The scales fell on her due to an explosion that either caused the crowd on the platform to panic (knocking the scales over) or caused the buckling of the platform itself (resulting in the scales overturning). Whichever event was the immediate cause, that event was due to the explosion of a package that fell under the wheels of the train, which (in turn) was caused by the efforts of employees to get a passenger (who was carrying the package of fireworks that slipped loose onto the tracks under the wheels) onto the train as it was departing the station. ${ }^{9}$

Manufacturing defects are generally IBLD cases, as a customer who (for example) buys a bottle of a beverage and finds a half-decomposed mouse in it needs only to show that it was more likely than not that the mouse got in the bottle before the product left the bottling plant; ${ }^{10}$ there is no need to consider how frequently this might occur. Finally, even though the number of casualties in an airplane crash may be in the hundreds, the National Transportation Safety Board attempts to use engineering analysis and science to describe the causal chain and provide reasons for the crash in terms of one or more specific failures (e.g., pilot error or airframe failure); such an event may lead to lawsuits, but these are not PBLD lawsuits simply because there is a mass of affected people.

${ }^{8}$ In re An Arbitration Between Polemis and Another and Furness, Withy \& Co. Ltd., 3 K.B. 560 (1921).

${ }^{9}$ Palsgraf v. Long Island Railroad Co., 248 N.Y. 339 (1928). For a discussion of some of the above details and the legal ramifications of this case, see Posner (1990) and Goldberg, et. al. (2004).

10 Shoshone Coca-Cola Bottling Co. v. Dolinski, 82 Nev. 439 (1966). 
Even when "but for" arguments may be confounded by the presence of multiple sufficient sources of harm, ${ }^{11}$ some cases provide discussions of causation that rely exclusively on the actions, and the likely stand-alone consequences of those actions, for the different sources. For example, in Summers v. Tice, et. al. ${ }^{12}$, even though there was no evidence of conspiracy, the defendants (Tice and Simonson) where held to be jointly liable when they (essentially simultaneously) discharged their weapons towards Summers while all three were hunting quail. Only one gun discharged the shot that wounded Summer's eye, but the court held that the burden of proof should be shifted to the defendants (that is, to show which specific gun was the actual source of the harm), relieving the plaintiff of having to prove who caused the injury, given the clear linkage of both defendants' actions to the harm suffered by the plaintiff.

In contrast, our model of PBLD assumes that the defendant is more likely to be found liable in a given case if the exposed population is found to have experienced a higher frequency of harm. Information about the experience of exposed populations is often introduced to argue for general causation (that is, exposure is capable of causing the kind of harm the plaintiff experienced). According to the Reference Manual on Scientific Evidence (2000), "Judges and juries increasingly are presented with epidemiologic evidence as the basis of an expert's opinion on causation. In the courtroom, epidemiologic research findings are offered to establish or dispute whether exposure to an agent caused a harmful effect or disease."13 Since a plaintiff will also have to establish specific causation (that is, exposure caused her specific harm, possibly attested to by a medical expert who

${ }^{11}$ See Goldberg, et. al., (2004), for a recent discussion of multiple necessary, and multiple sufficient, sources of harm.

12 Summers v. Tice, et. al. 33 Cal. 2d 80 (1948).

13 Green, et. al. (2000, p. 335). 
examined the plaintiff), the strength of evidence about general causation will be influential but need not be determinative. It does appear, however, that strong general causation evidence (e.g., a high rate of relative risk for a product compared with, say, natural causes of a disease) can substitute for weaker specific causation evidence. ${ }^{14}$

An example of a virtually pure PBLD case involves the swine flu vaccination program; the following discussion is based on the district court's opinion in Manko v. United States. ${ }^{15}$ In 1976 the U.S. government instituted an immunization program against the swine flu. To induce pharmaceutical companies to manufacture the vaccine, the federal government assumed all liability for injuries stemming from its use. The program began on October 1, 1976 and was halted on December 18, 1976, when data collected by the Center for Disease Control (which was monitoring the program) suggested that the vaccine might be causing Guillan-Barre Syndrome (GBS), a neurological disorder resulting in paralysis from which most, but not all, patients recover.

Both parties agreed that Louis Manko had received the vaccine and had contracted GBS; moreover, the defendant (the U.S. government) had agreed that the plaintiff did not need to prove negligence in order to establish liability. The only issue in dispute was whether the swine flu vaccine caused the plaintiff's GBS, which had been diagnosed thirteen weeks after he received the vaccine. ${ }^{16}$ "In the context of this case, the epidemiologists testifying for both plaintiff and defendant

${ }^{14}$ See Green, et. al. (2000, pp. 383-4) though, as noted therein, this substitution possibility is not uniformly accepted.

${ }^{15}$ Manko v. United States, 636 F. Supp. 1419 (WD MO, 1986); affirmed $8^{\text {th }}$ Cir. 1987.

16 Based on a study conducted by the CDC, the U.S. government had already conceded liability for cases of GBS arising within ten weeks of vaccination. "Therefore, claimants had to demonstrate only that they had received a vaccination and that their subsequent episode of GBS occurred within ten weeks of receiving the influenza vaccine" (Ginzburg, 1986, p. 429). 
agree that if the relative risk of contracting GBS among the population receiving the swine flu immunization exceeds 2 , it is more likely than not that the swine flu immunization caused the GBS." ${ }^{\prime 17}$ Thus, the trial over liability was reduced to a battle of statistical and epidemiological experts over whether the vaccine (at least) doubled the risk of contracting GBS thirteen weeks following vaccination.

All of the experts relied on data collected by the CDC during the conduct of the vaccination program, although some of it was incomplete and disputes arose regarding how to deal with the flawed data. Moreover, since the CDC had discontinued its rigorous data collection when the program was halted, the litigants' experts used different procedures to project the extent of unreported cases (in both the vaccinated and unvaccinated populations) into the relevant time period, and predictably came to different conclusions. In an interesting twist, the district court imposed discovery sanctions on the U.S. government for its refusal to make available to the plaintiff's experts' documents that might have clarified some of the incomplete observations. The nature of the court-imposed sanction was to interpret vague or incomplete data in the most favorable light for the plaintiff. "As a result of these sanctions, ... a sufficient number of long onset cases are identified to cause the relative risk of contracting GBS thirteen weeks after receiving a swine flu vaccination to far exceed 2."18 Even after correcting for the risk that the plaintiff had independently contracted GBS from an intervening episode of the flu, the district court concluded: "Therefore, plaintiff's GBS contracted in January 1977 was caused by the October 1976 swine flu vaccination.”19

\footnotetext{
${ }^{17}$ Manko, p. 1434.

18 Manko, p. 1438.

19 Manko, p. 1438.
} 
IBLD and PBLD in the Context of Fault, Design Defect, and Failure-to-Warn

For an example of IBLD in the context of fault, consider the famous paragraph of U.S. $v$ Carroll Towing Co. ${ }^{20}$ which gives rise to the "Hand Rule," wherein Judge Hand makes clear that the presence of an attendant (the "bargee") could be expected to reduce the probability of the accident. This is an assertion of IBLD since it is the individual (or in this case, the firm's agent) whose extended absence can be viewed as increasing the expected loss, leading to a Hand Rule-based assertion of fault.

However, a finding of fault can reflect PBLD considerations in a variety of ways. According to Goldberg, et. al. (p. 857), one conception of design defect is based on a risk-utility test: “... a product is defectively designed if the risks of its design outweigh its utility." Thus, observational evidence regarding the safety benefit of a design change would presumably be pertinent to the liability calculus: the higher the fraction of individuals that have been harmed by the current design, the more likely it will be found that an alternative design (one that is safer, but perhaps more costly) should have been chosen instead. In some cases, no alternative design is available to the firm but its product may be found to be unreasonably dangerous. For instance, Merck's pain reliever Vioxx was supposed to be at least as effective as Naproxen, but with fewer adverse gastrointestinal side effects. In on-going litigation, it is alleged that Vioxx substantially increases the risk of heart attack, which (under a risk-utility test) may render it unreasonably dangerous (since an allegedly safer and effective substitute exists in Naproxen), in which case Vioxx should not have been sold (or should not have continued to be sold, after Merck is alleged to have discovered its true risks). Finally, in the case of failure to warn (see Goldberg, et. al., p. 926) : “...the product is defective not because

${ }^{20}$ U. S. v Carroll Towing Co. 159 F.2d 169 (2 ${ }^{\text {nd }}$ Cir., 1947), p. 173. 
of how it has been designed or made, but because it should have been delivered with more information for consumers about the dangers associated with it, and how to use it safely." Again, this suggests that aggregate experience should be relevant: the higher the fraction of users that has been harmed by the product (which fraction could have been reduced by a warning), the more likely it will be found that a warning should have been provided.

For an example involving a design defect, in Jarvis $v$ Ford $^{21}$ an appeals court ruled that a jury had properly found that a design flaw in the cruise control mechanism of Ford Motor Company's 1991 Aerostar had led to Kathleen Jarvis's accident. The court stated (p. 38): “To prove negligence, Jarvis was not required to establish what specific defect caused the Aerostar to malfunction." Furthermore, the court argued that the presence of numerous similar accounts supported the finding of negligence (p. 54):

"Jarvis's testimony, the testimony of other Aerostar owners who had similar experiences, and evidence of hundreds of other reported cases of sudden acceleration in Aerostars, combined with an expert's scientific explanation of how cruise control may have malfunctioned and of an inexpensive remedy, were all found admissible by the district court. Together, this evidence provided the jury with a sufficient evidentiary basis to reasonably conclude that the cruise control mechanism had been defectively designed."

The recent settlements entered into between various dioceses of the Catholic Church with those claiming they were (as children) molested by priests appears to be a good example of PBLD, especially as regarding the possibility of finding fault on the part of Church officials if the cases went to trial. Some states have extended civil liability by adjusting the statute of limitations so as to allow more filings than would otherwise be possible. ${ }^{22}$ One effect of this has been to increase

${ }^{21}$ Jarvis v Ford Motor Co., 283 F.3d 33 (2 ${ }^{\text {nd }}$ Cir., 2002).

${ }^{22}$ For example, in 1992 California added a year to the statute of limitations for (civil) suits claiming sexual abuse of children; this added a number of cases in the Los Angeles, as well as other, 
substantially the number of cases filed, as victims were able to learn that they were not isolated cases of abuse (since early settlements were concluded with confidentiality agreements) and were more willing to come forward. The onslaught of cases (and the substantially increased level of average compensation paid $)^{23}$ has also led many to conclude that Church authorities contributed significantly to the harm via a policy of hiding the crimes from the police and re-assigning accused priests to activities involving youth. Here there is an argument both of individual culpability (on the part of specific priests) as well as of vicarious liability on the part of officials who not only did not correct the problem, but whose actions enhanced its impact on unsuspecting parishoners. It is likely that only Church authorities have an accurate estimate of organizational culpability. Here, frequency-ofharm information appears to be contributing to the success of lawsuits (and, in this case, obtaining much larger settlements), as the priests themselves are essentially judgment-proof.

\section{An IBLD Model of Suit, Settlement, and Trial}

The model in this section is based on Bebchuk's (1984) screening model of settlement bargaining, ${ }^{24}$ modifying it to allow for filing decisions. Let $\lambda$ be the likelihood of a defendant $\mathrm{D}$ being found liable if a plaintiff $P$ takes $D$ to trial. Assume that $\lambda \in[0,1]$, that its actual value

dioceses. Recently, Connecticut and Maryland have substantially extended the civil statute of limitations, including making the new limitations retroactive.

23 Recent settlement amounts in Los Angeles have averaged over one million dollars, as compared with settlements in earlier cases in Boston which were in the tens of thousands of dollars. For a description of the cases involving the Boston Archdiocese, see Investigative Staff of the Boston Globe (2002). These are primarily individual suits, though some have been consolidated for settlement purposes.

${ }^{24}$ Surveys that discuss this model and some of the extensions include Hay and Spier (1998) and Daughety (2000). 
(denoted as $\Lambda$ ) is known only to $\mathrm{D}$ in advance of trial (i.e., $\Lambda$ is private information for $\mathrm{D}$ during bargaining) and will be revealed at trial. Further, assume that it is common knowledge for $\mathrm{P}$ and $\mathrm{D}$ that the possible values of $\lambda$ follow a continuous, differentiable distribution $\mathrm{F}(\bullet)$, with associated density $f(\bullet)$, and that $f(\bullet)$ is positive and continuous everywhere on $[0,1]$. Thus, $F$ is the "prior" distribution over the possible likelihoods of $\mathrm{D}$ being found liable. We view $\mathrm{F}$ as commonly known, perhaps due to publically-available information about the underlying phenomenon of interest. Since this paper will be considering some alternative means by which posterior distributions arise, the notation below will keep track of what distribution is being employed in a calculation.

We consider the following game. P consults her attorney, PA, and together they choose a take-it-or-leave-it demand, denoted as $\mathrm{S}_{\mathrm{F}}$, to make of D. Assume that $\mathrm{P}$ will pay PA on a contingency-fee basis and that if there is a trial, PA will incur a trial $\operatorname{cost} \mathrm{c}_{\mathrm{P}}>0$ while $\mathrm{D}$ will incur a trial cost $\mathrm{c}_{\mathrm{D}}>0$, with $\mathrm{C} \equiv \mathrm{c}_{\mathrm{P}}+\mathrm{c}_{\mathrm{D}} \cdot{ }^{25}$ We assume that $\mathrm{P}$ ultimately will make the decision whether to take the case to trial (or not) should $\mathrm{D}$ reject the demand $\mathrm{S}_{\mathrm{F}}$. However, PA makes the decision as to whether or not to take P's case to begin with, knowing the costs that will be incurred if trial ensues. Initially we ignore the cost of filing a suit, denoted as $\mathrm{K}>0$, but we return to this below when discussing the filing of suits. ${ }^{26}$ Further, we will ignore the exact division of the returns from settlement or trial between $\mathrm{P}$ and PA, but simply assume that $\mathrm{P}$ and PA can come to an agreement specifying a contingency fee for PA if the ex ante expected return (accounting for $\mathrm{c}_{\mathrm{P}}$ and $\mathrm{K}$ ) is non-

${ }^{25}$ Since D would pay his attorney on a flat fee basis, we need not concern ourselves with addressing D's attorney.

26 We view $\mathrm{K}$ as including not only the simple act of filing some papers, but also the disutility of pursuing a case. For example, in cases such as the lawsuits over child abuse by priests, $\mathrm{K}$ is likely to include a large disutility element for some potential plaintiffs. Thus, $\mathrm{K}$ need not be a trivial cost. 
negative; if the ex ante expected return is negative, PA chooses not to take the case and $\mathrm{P}$ also exits the game. Finally, we assume that the harm suffered by $P$, denoted as $\delta$, is common knowledge to all parties and is verifiable in court. We further assume that there is some minimal level of harm, denoted as $\underline{\delta}>0$.

In this section we consider a take-it-or-leave-it screening game, so this means that $\mathrm{P}$ and PA make a demand $\mathrm{S}_{\mathrm{F}}$ of D. D's expected cost if the case goes to trial is $\Lambda \delta+\mathrm{c}_{\mathrm{D}}$, so if $\mathrm{S}_{\mathrm{F}} \leq \Lambda \delta+\mathrm{c}_{\mathrm{D}}$, then $\mathrm{D}$ can do no better at trial and therefore accepts the demand (we will assume that he accepts the demand if indifferent). In this case, $\mathrm{S}_{\mathrm{F}}$ is transferred from $\mathrm{D}$ to $\mathrm{P}$ and $\mathrm{PA}$, who will split it based on their earlier agreement; PA does not pay the cost $\mathrm{c}_{\mathrm{p}}$. If, however, $\mathrm{S}_{\mathrm{F}}>\Lambda \delta+\mathrm{c}_{\mathrm{D}}$, then $\mathrm{D}$ rejects the demand. Since the fee arrangement between P and PA is a previously-negotiated contingency fee, $\mathrm{P}$ will decide to go to trial. At trial, D loses with probability $\Lambda$, and if he loses he makes a transfer of $\delta$ to $\mathrm{P}$ and PA (who will split it based on their earlier agreement); whether D wins or loses, PA and D will each pay their respective trial costs.

Not knowing $\Lambda$ before trial, $\mathrm{P}$ and $\mathrm{PA}$ wish to pick a demand to maximize the expected value of the transaction, which includes both the ex ante expected cost of trial and the ex ante expected settlement payment. If $\mathrm{P}$ and $\mathrm{PA}$ wish to make a demand $\mathrm{S}_{\mathrm{F}}$, then this is equivalent to inducing a marginal type $\lambda=\left(\mathrm{S}_{\mathrm{F}}-\mathrm{c}_{\mathrm{D}}\right) / \delta$ who is just indifferent between trial and settlement. If D's actual type $\mathrm{t}$ is less than this value, then trial occurs and the plaintiff receives $\left(\mathrm{t} \delta-\mathrm{c}_{\mathrm{P}}\right)$; the ex ante expected cost associated with this outcome is $\int_{0}^{\lambda}\left(t \delta-c_{\mathrm{P}}\right) \mathrm{f}(\mathrm{t}) \mathrm{dt}$. On the other hand, if D's actual type equals or exceeds the marginal type, then $\mathrm{D}$ will accept the demand $\mathrm{S}_{\mathrm{F}}=\lambda \delta+\mathrm{c}_{\mathrm{D}}$. This occurs with probability $1-\mathrm{F}(\lambda)$, so the second term in the ex ante expected payoff is the expected settlement payment of $(\lambda \delta$ $\left.+c_{D}\right)(1-F(\lambda))$. Let $Z(\lambda ; F)$ be the joint payoff to $P$ and PA if the marginal type of $D$ is $\lambda$ and the 
distribution of the likelihood of liability is F. Thus,

$$
\mathrm{Z}(\lambda ; \mathrm{F}) \equiv \int_{0}^{\lambda}\left(\mathrm{t} \delta-\mathrm{c}_{\mathrm{P}}\right) \mathrm{f}(\mathrm{t}) \mathrm{dt}+\left(\lambda \delta+\mathrm{c}_{\mathrm{D}}\right)(1-\mathrm{F}(\lambda))
$$

The decision problem for $\mathrm{P}$ and PA is therefore to find a marginal type, $\lambda^{*}$, that maximizes $\mathrm{Z}(\lambda ; \mathrm{F})$; the corresponding optimal demand is $\mathrm{S}_{\mathrm{F}}^{*}=\lambda * \delta+\mathrm{c}_{\mathrm{D}}$.

Assuming an interior solution to this optimization problem, the first-order condition for maximizing $Z(\lambda ; F)$, evaluated at $\lambda^{*}$, can be written as follows:

$$
\mathrm{f}\left(\lambda^{*}\right) /\left(1-\mathrm{F}\left(\lambda^{*}\right)\right)=\delta / C \text {. }
$$

The left-hand-side is the "hazard function" for the distribution $F$, which is $f(\lambda) /(1-F(\lambda))$, evaluated at $\lambda^{*}$, while the right-hand-side is the level of P's damages divided by the sum of the court costs.

In order to ensure that there is a unique interior solution $\lambda^{*}$, we make the following two assumptions.

Assumption 1: $f(\lambda) /(1-F(\lambda))$ is strictly increasing in $\lambda$.

Assumption 2: $\mathrm{f}(0)<\delta / C$.

The effect of enforcing these two assumptions is illustrated in Figure 1 below. Assumption 1 is a standard assumption used in screening models and is a property of a variety of possible Fdistributions. ${ }^{27}$ Note that $f(0) /(1-F(0))$ is simply $f(0)$, while $f(\lambda) /(1-F(\lambda))$ becomes arbitrarily large as $\lambda$ goes to 1 (since $F(1)=1$ ), so Assumption 2 is needed to guarantee an interior optimum. We formalize these observations in the following proposition.

Proposition 1: Under Assumptions 1 and 2, there exists a unique $\lambda^{*} \in(0,1)$ that maximizes

$$
Z(\lambda ; F) \text {. This solution satisfies } f\left(\lambda^{*}\right) /\left(1-F\left(\lambda^{*}\right)\right)=\delta / C \text {. }
$$

27 See Bagnoli and Bergstrom (2005) for an extensive discussion of conditions that guarantee that a hazard function is strictly increasing in its argument, as well as a detailed review of when the property holds for a variety of well-known distributions. 


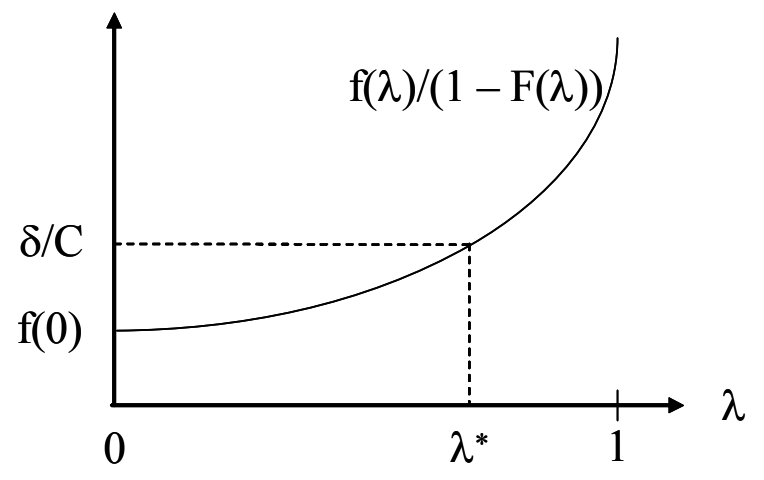

Figure 1: Using the Hazard Function to Find the Optimal Marginal Type

Thus, the equilibrium demand is $\mathrm{S}_{\mathrm{F}}^{*}=\lambda^{*} \delta+\mathrm{c}_{\mathrm{D}}$, and the joint payoff for $\mathrm{P}$ and $\mathrm{PA}$ (now accounting for the filing cost) is $\mathrm{Z}\left(\lambda^{*} ; \mathrm{F}\right)$ - K ; if this is non-negative, then a suit will be filed, the demand $\mathrm{S}_{\mathrm{F}}^{*}$ will be made, and a trial will occur with probability $\mathrm{F}\left(\lambda^{*}\right)$. Finally, if the defendant is of type $t$ then his payoff is $t \delta+c_{D}$ if $t<\lambda^{*}$ and $\lambda * \delta+c_{D}$ if $t \geq \lambda^{*}$.

Note that if Assumption 2 does not hold, then $f(0)$ is at or above $\delta / C$, meaning that the optimal decision for P and PA is to make a demand that pools all the types of D. Since the optimal value of $\lambda$ is therefore $\lambda^{*}=0$, the pooling offer is $\mathrm{S}_{\mathrm{F}}^{*}=\mathrm{c}_{\mathrm{D}}$ and all defendant types settle at this demand (this will also be the defendant's payoff). More precisely, as long as $\mathrm{c}_{\mathrm{D}}-\mathrm{K}$ is non-negative, a suit will be filed, $\mathrm{S}_{\mathrm{F}}^{*}$ will be D's court costs, $\mathrm{c}_{\mathrm{D}}$, and there will no trials occurring in equilibrium.

\section{An Example Using the Uniform Distribution}

To illustrate the foregoing, and for use in our examples of comparisons later, let $\mathrm{F}$ be the uniform distribution, so that $f(\lambda)=1$, and $F(\lambda)=\lambda$. This means that the hazard function $f(\lambda) /(1-F(\lambda))=1 /(1-\lambda)$, which is strictly increasing and asymptotic to the vertical line at $\lambda=1$. Initially, consider the case wherein Assumption 2 holds; since $\mathrm{f}(0)=1$, we initially require that $\delta$ $>$ C. Then there is an interior solution to the problem of maximizing $Z(\lambda ; F)$, which is $\lambda^{*}=1-C / \delta$. 
Therefore, $\mathrm{S}_{\mathrm{F}}^{*}=\lambda * \delta+\mathrm{c}_{\mathrm{D}}=\delta-\mathrm{c}_{\mathrm{P}}$, and the joint payoff to $\mathrm{P}$ and PA is $\mathrm{Z}\left(\lambda^{*} ; \mathrm{F}\right)=(1-\mathrm{C} / \delta)^{2}(\delta / 2)+\mathrm{c}_{\mathrm{D}}$; the probability of trial is $\mathrm{F}\left(\lambda^{*}\right)=1-\mathrm{C} / \delta$. Since the ex ante expected joint return (ignoring filing costs) to $\mathrm{P}$ and $\mathrm{PA}$ is positive, there is always an agreement that $\mathrm{P}$ and $\mathrm{PA}$ could come to concerning sharing the joint payoff, provided it covers the cost of filing. If we account for the filing cost, K, then $\mathrm{Z}\left(\lambda^{*} ; \mathrm{F}\right)-\mathrm{K}$ is non-negative if and only if :

$$
(1-\mathrm{C} / \delta)^{2}(\delta / 2) \geq \mathrm{K}-\mathrm{c}_{\mathrm{D}} .
$$

If $\mathrm{K}<\mathrm{c}_{\mathrm{D}}$, then (3) always holds, so the only lower bound on the types who would file is the interiority condition that $\delta>\mathrm{C}$. If $\mathrm{K}-\mathrm{c}_{\mathrm{D}}>0$, then condition (3) at equality yields a quadratic in $\delta$ which can be shown to have one root that further restricts the set of $\delta$-values that would file, namely $\delta \geq \mathrm{K}+\mathrm{c}_{\mathrm{P}}+\left[\left(\mathrm{K}+\mathrm{c}_{\mathrm{P}}\right)^{2}-\mathrm{C}^{2}\right]^{1 / 2}$. Finally, as indicated above, if Assumption 2 fails to hold (i.e., $\mathrm{C} \geq$ $\delta>\underline{\delta}$ ) then the joint optimum for P and PA is a boundary solution with $\lambda^{*}=0$, meaning a pooling demand of $\mathrm{S}_{\mathrm{F}}^{*}=0 \times \delta+\mathrm{c}_{\mathrm{D}}=\mathrm{c}_{\mathrm{D}}$, which all types of $\mathrm{D}$ will accept. In this case, $\mathrm{Z}(0 ; \mathrm{F})=\mathrm{c}_{\mathrm{D}}$, so a case is filed if and only if $c_{D} \geq K$.

\section{Deriving a PBLD Model of Suit, Settlement, and Trial}

We now turn to the case in which the likelihood that $\mathrm{D}$ will be found liable depends on the fraction of the exposed population that has been harmed, denoted as $\alpha \in[0,1]$. In what follows we assume that this fraction represents the probability that $\mathrm{D}$ is found liable; this is a simplification, since one might expect that even moderate values of $\alpha$ might readily map to a very high likelihood of being found liable. In the Appendix we show that (essentially) identical results to those shown in this section and in Section 5 would hold in an analysis wherein liability was modeled as any differentiable, strictly increasing function of $\alpha$; we provide more detail on this issue in Section 6. 
However, introducing such a generalization at this point would complicate the exposition without adding any insight. Since the primary purpose of the paper is to compare the incentives for suit, settlement, and trial under PBLD versus IBLD, for simplicity of exposition in the main text we will use $\alpha$ to model the probability of liability. ${ }^{28}$

To maintain comparability with the IBLD model and thereby isolate the effect of the externality of interest, we assume that the prior probability distribution over D's likelihood of being found liable is $F(\alpha)$, and that this is common knowledge based on publically-available information. For example, in the case of pharmaceuticals, there are likely to be animal studies and some (relatively small) human studies as required by the FDA. The firm may or may not have private information about $\alpha$ at this point, depending on whether it has released all relevant studies to the public. However, marketing the drug to the general public constitutes a large-scale study, in which $\alpha$ is realized. At this point the firm is likely to observe the actual value of $\alpha$ as it receives reports of adverse side effects (and possibly lawsuits) back from the field, while individual users of the drug will remain uncertain about $\alpha$.

A plaintiff who does not observe $\alpha$ directly can use the fact that she herself was harmed to update her beliefs about the distribution of $\alpha$ (as was illustrated in Section 1). To see this, suppose there are $\mathrm{N}$ users of a product and that $\alpha \mathrm{N}$ users are harmed. Since each consumer is equally likely to be among those harmed, the conditional probability of a particular consumer being harmed (given that $\alpha \mathrm{N}$ are harmed) is $\alpha \mathrm{N} / \mathrm{N}=\alpha$. The probability (density) that $\alpha \mathrm{N}$ consumers are harmed is given

28 As mentioned earlier, there can be multiple possible sources of cause for a harm. For example, there might be a natural rate of contracting a type of cancer in the population. A suitable modification of the model could readily account for this background effect in both the exposed and unexposed populations. We have suppressed this background possibility so as to keep the exposition as simple as possible. 
by $f(\alpha)$. Thus, the unconditional probability (density) of both a particular consumer being harmed and $\alpha \mathrm{N}$ users being harmed is given by $\alpha \mathrm{f}(\alpha)$. Finally, the unconditional probability that a particular consumer will be harmed is given by $\int_{0}^{1} \mathrm{tf}(\mathrm{t}) \mathrm{dt}$; this is simply the mean of the prior distribution, which we denote as $\mu_{\mathrm{F}}$.

Combining these expressions using Bayes' Rule, a particular consumer who is harmed has a posterior density over $\alpha$ that is given by $\mathrm{g}(\alpha) \equiv \alpha \mathrm{f}(\alpha) / \int_{0}^{1} \mathrm{tf}(\mathrm{t}) \mathrm{dt}=\alpha \mathrm{f}(\alpha) / \mu_{\mathrm{F}}$. Let $\mathrm{G}(\alpha)$ be the distribution associated with the density $\mathrm{g}(\alpha)$, and let $\mu_{\mathrm{G}}$ denote the expected value of $\alpha$ using the distribution G. As stated below in Proposition 2, the distribution G first-order stochastic dominates (FOSD) the distribution $F$, meaning that $G(\alpha) \leq F(\alpha)$ for all $\alpha$, with strict inequality for at least some sub-interval of $[0,1]$.

Proposition 2. Distribution G first-order stochastic dominates distribution F; consequently,

$$
\mu_{\mathrm{G}}>\mu_{\mathrm{F}} .
$$

This mathematical characterization, that G FOSD F, is the same as the earlier intuitive characterization: the posterior distribution places higher weight on the higher values of the random variable (namely, the fraction of the exposed population harmed) than does the prior distribution. Using the uniform example from Section $3, \mathrm{f}(\alpha)=1$ for $\alpha \in[0,1]$, so $\mathrm{F}(\alpha)=\alpha$ and $\mu_{\mathrm{F}}=1 / 2$. Therefore, $\mathrm{g}(\alpha)=\alpha \times 1 /(1 / 2)=2 \alpha, \mathrm{G}(\alpha)=\alpha^{2}$ and $\mu_{\mathrm{G}}=2 / 3$. Note that $\mathrm{G}(0)=\mathrm{F}(0)=0, \mathrm{G}(1)=\mathrm{F}(1)=$ 1, and $\mathrm{G}(\alpha)<\mathrm{F}(\alpha)$ for $0<\alpha<1$; this is illustrated in Figure 2 below, where the Figure 2(a) illustrates the density functions $f(\alpha)$ and $g(\alpha)$, while Figure 2(b) illustrates the probability distributions $\mathrm{F}(\alpha)$ and $\mathrm{G}(\alpha)$.

A moment's reflection on the material in Section 3 makes it clear that $\int_{0}^{\alpha}\left(\mathrm{t} \delta-\mathrm{c}_{\mathrm{P}}\right) \mathrm{g}(\mathrm{t}) \mathrm{dt}+$ $\left(\alpha \delta+c_{D}\right)(1-G(\alpha))$ is the joint payoff to $P$ and PA if the marginal type of D who is just indifferent 


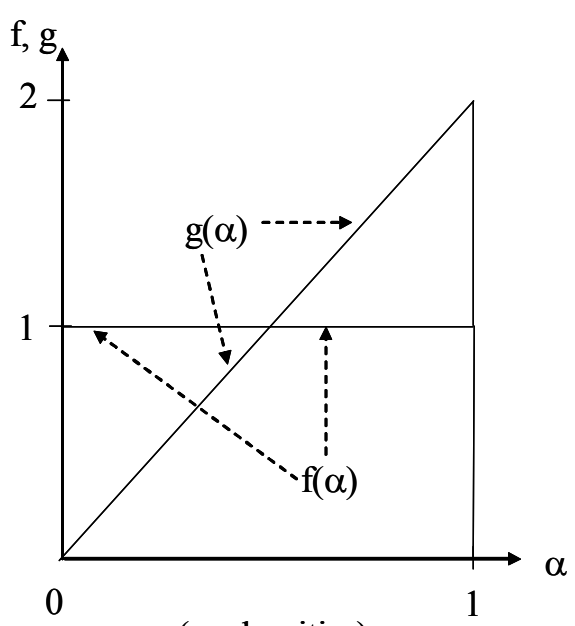

(a: densities)

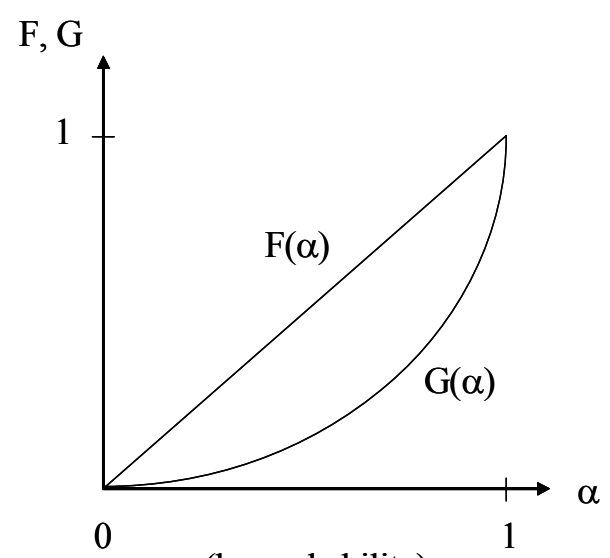

(b: probability)

Figure 2: Comparison of Prior (f, F) and Posterior (g, G) Functions

between trial and settlement is $\alpha$ and the distribution of the likelihood of liability is G. That is, the joint payoff to P and PA in the PBLD model has the same form as that in the IBLD model, except for the judicious replacement of symbols as shown in equation (4) below:

$$
\mathrm{Z}(\alpha ; \mathrm{G}) \equiv \int_{0}^{\alpha}\left(\mathrm{t} \delta-\mathrm{c}_{\mathrm{P}}\right) \mathrm{g}(\mathrm{t}) \mathrm{dt}+\left(\alpha \delta+\mathrm{c}_{\mathrm{D}}\right)(1-\mathrm{G}(\alpha)) .
$$

The first-order condition for this problem is parallel to the earlier one specified in equation (2); the following proposition formalizes this.

Proposition 3. There exists at least one value $\alpha^{*} \in(0,1)$ that maximizes $Z(\alpha ; G)$. This solution satisfies $\mathrm{g}\left(\alpha^{*}\right) /\left(1-\mathrm{G}\left(\alpha^{*}\right)\right)=\delta / \mathrm{C}$.

There are two qualitative differences between Proposition 1 and Proposition 3 that are worthy of comment. First, Proposition 3 does not assume that the hazard function $\mathrm{g}(\alpha) /(1-\mathrm{G}(\alpha))$ is strictly increasing; this is not needed. In fact the hazard function $\mathrm{g}(\bullet) /(1-\mathrm{G}(\bullet))$ need not be strictly increasing even if $\mathrm{f}(\bullet) /(1-\mathrm{F}(\bullet))$ is strictly increasing. However, $\mathrm{g}(\bullet) /(1-\mathrm{G}(\bullet))$ starts at zero (since $\mathrm{g}(0)=0 \times \mathrm{f}(0) / \mu_{\mathrm{F}}=0$ and $\mathrm{G}(0)=0$ ), and eventually is asymptotic to the vertical line at $\alpha=1$ (since $\mathrm{g}(1)>0$ and $\mathrm{G}(1)=1)$. This means it must cross the horizontal line at $\delta / C$ at least once. Further, 
$\mathrm{g}(0)=0<\delta / C$, so we know that all optima are interior.

Second, Proposition 3 does not claim that there is a unique solution to the first-order condition for maximizing $\mathrm{Z}(\alpha ; \mathrm{G})$; the lack of monotonicity of $\mathrm{g}(\bullet) /(1-\mathrm{G}(\bullet))$ means that there might be multiple optima, some local minima and some local maxima (this is illustrated in Figure 3 below). Henceforth we will use $\alpha^{*}$ to denote the value of $\alpha$ that provides the global maximum of $Z(\alpha ; G)$; in the unlikely event that there are multiple such values, we will take $\alpha^{*}$ to be the minimum value of $\alpha$ that provides the global maximum of $Z(\alpha ; G)$. Thus, the joint payoff for $P$ and $P A$ is $Z\left(\alpha^{*} ; G\right)$; accounting for filing costs, a case will be brought as long as $Z\left(\alpha^{*} ; G\right)-K$ is non-negative.

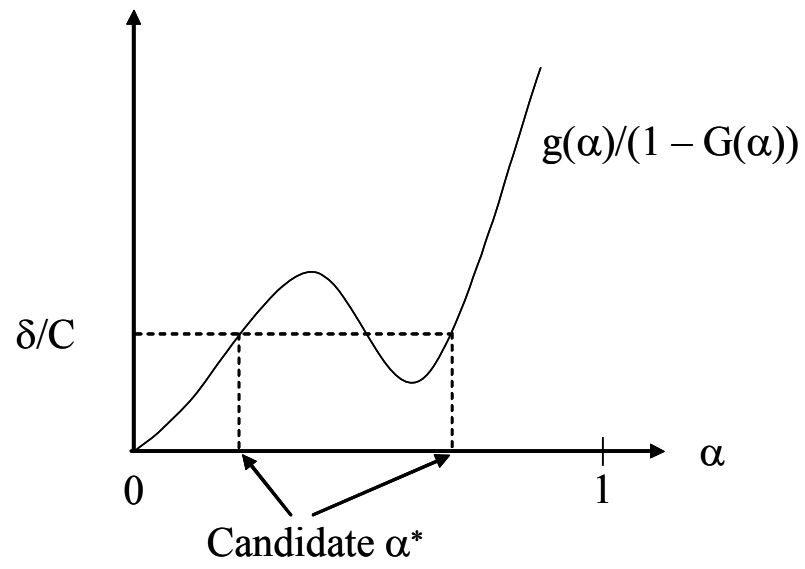

Figure 3: Using the PBLD Hazard Function to Find the Optimal Marginal Type

As long as a case is brought there is no possibility of pooling in this model, since the global optimum $\alpha^{*}$ is always interior; the demand made of $\mathrm{D}$ is $\mathrm{S}_{\mathrm{G}}^{*}=\alpha^{*} \delta+\mathrm{c}_{\mathrm{D}}$. As an illustrative example, recall the discussion in Section 3 wherein $\mathrm{F}$ was taken to be the uniform distribution. In this case the solution to the first-order condition specified in Proposition 3 is $\alpha^{*}=\left(1+C^{2} / \delta^{2}\right)^{1 / 2}-C / \delta>0$, so the demand made of $\mathrm{D}$ is $\mathrm{S}_{\mathrm{G}}^{*}=\alpha^{*} \delta+\mathrm{c}_{\mathrm{D}}=\left(\mathrm{C}^{2}+\delta^{2}\right)^{1 / 2}-\mathrm{c}_{\mathrm{P}}$. 
5. Comparing the Results from the Two Alternative Models

As with the earlier propositions, the proofs of the propositions below, which detail the comparisons of the results of the two models, are in the Appendix. In what follows we provide an intuitive discussion of the results.

\section{Comparing the IBLD and PBLD Optima}

Fortunately, the lack of monotonicity of $\mathrm{g}(\bullet) /(1-\mathrm{G}(\bullet))$ is not really a problem, as shown by the following two propositions and as illustrated in Figure 4 below.

Proposition 4. Both hazard functions go to infinity as $\alpha$ goes to 1 ; otherwise, $g(\alpha) /(1-G(\alpha))$

$$
<\mathrm{f}(\alpha) /(1-\mathrm{F}(\alpha)) \text { for all } \alpha \in[0,1) .
$$

In other words, the hazard function associated with $\mathrm{G}$ always lies below that associated with $\mathrm{F}$; this is illustrated in Figure 4. This has the immediate implication that the joint payoff-maximizing marginal type in the PBLD model, $\alpha^{*}$, always lies to the right of the joint payoff-maximizing marginal type in the IBLD model, $\lambda^{*}$. This further implies that the PBLD demand is always greater than that made in the IBLD model, as stated in the following proposition.

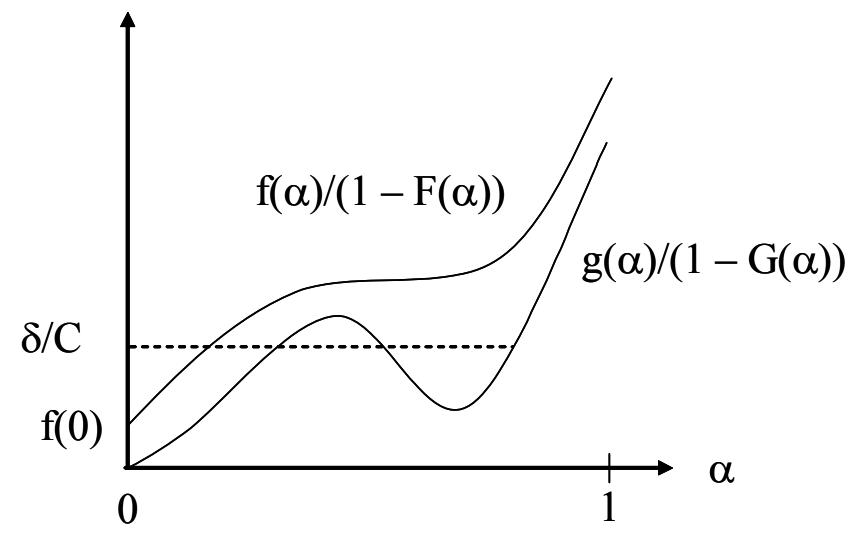

Figure 4: Comparison of Hazard Functions 
Proposition 5. $\alpha^{*}>\lambda^{*}$; consequently, $\mathrm{S}_{\mathrm{G}}^{*}=\alpha^{*} \delta+\mathrm{c}_{\mathrm{D}}>\mathrm{S}_{\mathrm{F}}^{*}=\lambda^{*} \delta+\mathrm{c}_{\mathrm{D}}$.

\section{Comparing Payoffs and Filing Decisions}

We can further exploit the result in Proposition 2, that G first-order stochastic dominates F to obtain the following ranking of payoffs.

Proposition 6. $Z\left(\alpha^{*} ; G\right)>Z\left(\lambda^{*} ; F\right)$; that is, the combined expected payoff to $\mathrm{P}$ and PA is higher in the PBLD model than in the IBLD model.

To characterize the filing decision (which P and PA are assumed to make jointly), we indicate the maximized payoff's dependence on the level of damages, $\delta$, and incorporate the filing cost, $\mathrm{K}$. For the IBLD model, a suit will be filed whenever $\mathrm{Z}\left(\lambda^{*} ; \mathrm{F}, \delta\right)-\mathrm{K} \geq 0$. On the other hand, for the PBLD model, a suit will be filed whenever $\mathrm{Z}\left(\alpha^{*} ; \mathrm{G}, \delta\right)-\mathrm{K} \geq 0$. Thus, for a given filing cost $\mathrm{K}$, the set of plaintiff damages levels that will result in suit is $\left[\delta_{\mathrm{F}}, \infty\right)$ for the IBLD model and $\left[\delta_{\mathrm{G}}, \infty\right)$ for the PBLD model. Finally, for a given value of $\delta$, the set of plaintiff filing cost levels that will result in suit is $\left[0, \mathrm{~K}_{\mathrm{F}}\right]$, where $\mathrm{K}_{\mathrm{F}} \equiv \mathrm{Z}\left(\alpha^{*} ; \mathrm{G}, \delta\right)$ in the IBLD model, and $\left[0, \mathrm{~K}_{\mathrm{G}}\right]$, where $\mathrm{K}_{\mathrm{G}} \equiv \mathrm{Z}\left(\alpha^{*}\right.$; $\mathrm{G}, \delta$ ) in the PBLD model, respectively. Summarizing, $\delta_{\mathrm{G}}$ and $\delta_{\mathrm{F}}$ are damages cut-offs for a given filing cost $\mathrm{K}$, while $\mathrm{K}_{\mathrm{G}}$ and $\mathrm{K}_{\mathrm{F}}$ are filing cost cut-offs for a given damages level $\delta$. The comparisons are summarized in Proposition 7.

Proposition 7. The propensity to file suit will be higher if liability-determination is population-based than if it is individual-based. Formally, for a given filing cost $\mathrm{K}$, it follows that $\delta_{\mathrm{F}}>\delta_{\mathrm{G}}$ when $\delta_{\mathrm{F}}>\underline{\delta}$ (and otherwise $\delta_{\mathrm{G}}=\delta_{\mathrm{F}}$ ); alternatively, for a given level of damages $\delta \geq \underline{\delta}$, it follows that $\mathrm{K}_{\mathrm{G}}>\mathrm{K}_{\mathrm{F}}$.

Comparing Incentives for the Defendant to Take Care

Proposition 6 implies that, in the case of suits that would be filed under either regime (i.e., 
suits with $\delta \geq \delta_{\mathrm{F}}$, defendants in such suits will face losses under PBLD that are no less than, and for some types greater than, those under IBLD. Moreover, the implication of Proposition 7 is that for plaintiffs with levels of damages that would fail to file under IBLD, but would file under PBLD (i.e., those $\delta$ in $\left[\delta_{\mathrm{G}}, \delta_{\mathrm{F}}\right)$ ), these suits would further add to the expected loss for all types of defendant. This means that PBLD increases the incentives for care on the part of a potential defendant. We return to this point below in the discussion of efficiency comparisons, but provide a summary of the foregoing payoff effects for the defendant in the following proposition.

Proposition 8. Holding the level of care (i.e., the distribution F) constant, the defendant is worse off in the PBLD model than the corresponding IBLD model. In particular, conditional on a suit being filed, the defendant of type t pays at least as much (and, for some values of $t$, strictly more) in the PBLD model than in the IBLD model. Moreover, more suits may be filed in the PBLD model than in the IBLD model.

\section{Likelihood of Trial and Social Efficiency Considerations and Comparisons}

Since we know from Proposition 5 that (from P and PA's perspective) both the optimal marginal type and the demand made of D under PBLD exceed the corresponding terms under IBLD, one is tempted to assume that, for suits that would be filed under both regimes (i.e., those with $\delta \geq$ $\delta_{\mathrm{F}}$ ), there will be more trials under PBLD than under IBLD. This is not necessarily true. The likelihood of trial in the IBLD model is $\mathrm{F}\left(\lambda^{*}\right)$ while the likelihood of trial in the PBLD model is $\mathrm{G}\left(\alpha^{*}\right)$. The two first-order conditions (see Propositions 1 and 3) tell us that:

$$
\mathrm{g}\left(\alpha^{*}\right) /\left(1-\mathrm{G}\left(\alpha^{*}\right)\right)=\delta / \mathrm{C}=\mathrm{f}\left(\lambda^{*}\right) /\left(1-\mathrm{F}\left(\lambda^{*}\right) .\right.
$$

Thus, for any given case that is filed under either regime, the likelihood of a trial under the PBLD regime is less than the likelihood of a trial under the IBLD regime (i.e., $\mathrm{G}\left(\alpha^{*}\right)<\mathrm{F}\left(\lambda^{*}\right)$ ) if and only 
if $\mathrm{f}\left(\lambda^{*}\right)<\mathrm{g}\left(\alpha^{*}\right)$. Since, by definition, $\mathrm{g}\left(\alpha^{*}\right)=\alpha^{*} \mathrm{f}\left(\alpha^{*}\right) / \mu_{\mathrm{F}}$, the condition for a lower likelihood of trial under PBLD than under IBLD is:

$$
\mathrm{f}\left(\lambda^{*}\right) / \mathrm{f}\left(\alpha^{*}\right)<\alpha^{*} / \mu_{\mathrm{F}} .
$$

For example, if $\mathrm{F}$ is the uniform distribution, then $\mathrm{f}\left(\lambda^{*}\right)=\mathrm{f}\left(\alpha^{*}\right)=1$, so condition (6) says that the likelihood of trial in this setting is lower under PBLD than under IBLD if $\alpha^{*}>1 / 2$. Upon substituting the value of $\alpha^{*}=\left(1+\mathrm{C}^{2} / \delta^{2}\right)^{1 / 2}-\mathrm{C} / \delta$ (see Section 4$)$, this becomes the condition $\delta>4 \mathrm{C} / 3$. Therefore, for a uniform F, if the level of damages is reasonably larger than the total costs of trial, and if that level of damages is enough to meet the condition on filing suits in the IBLD regime, then each such case is more likely to settle under PBLD than under IBLD.

More generally (since the density $\mathrm{f}$ is continuous on $[0,1]$ ), in the limit as $\delta$ becomes arbitrarily large, the left-hand-side of condition (6) must go to 1 since $\lambda^{*}$ and $\alpha^{*}$ both go to 1 , and the right-hand-side must go to $1 / \mu_{\mathrm{F}}>1$. Therefore, there is some finite level of damages (denoted as $\delta^{\mathrm{PBLD}}$ ) such that for fixed $\mathrm{C}$ and for all $\delta>\delta^{\mathrm{PBLD}}$, condition (6) must hold. Of course, the value $\delta^{\text {PBLD }}$ might be very large (though finite), and the inequality in condition (6) may hold for subintervals below this value (and then fail for other sub-intervals). The implication is that, if the level of damages is high enough relative to total court costs, then (in the sense of minimizing trial costs given suit) PBLD is more efficient than IBLD for cases that would be brought under either regime. Some stronger sufficient conditions on $\mathrm{f}(\bullet)$ that imply condition (6) will hold when $\delta$ is large enough include: 1) $\mathrm{f}(\bullet)$ is always constant; or 2$) \mathrm{f}(\bullet)$ is increasing; or 3$) \mathrm{f}(\bullet)$ is simply eventually increasing (but bounded, so as to maintain continuity) as might occur in some U-shaped densities that exist.

Note, however, that the overall question of comparing the expected frequency of trial under the two regimes is complicated by several factors. First is the fact that there is a range of harms 
(those between $\delta_{\mathrm{G}}$ and $\delta_{\mathrm{F}}$ ) for which cases would be filed under the PBLD regime and not under the IBLD regime. Further, and this is yet more striking, note that while pooling might occur under IBLD, if a suit is filed under PBLD, there is always a positive probability of a trial. To see this, consider a suit such that $\delta=\mathrm{C}$. In this case $\lambda^{*}=0$ but $\alpha^{*}>0$; thus there will be no trials under IBLD (all cases will settle), but trials are possible under PBLD. Therefore, the basic question of whether there are likely to be more trials in one regime or the other could go either way, with condition (6) indicating the relationship among $\lambda^{*}, \alpha^{*}$ and the particulars ${ }^{29}$ of the F-distribution in order that PBLD be more efficient than IBLD when $\delta$ is in $\left[\delta_{\mathrm{F}}, \infty\right)$. Finally, incentives for increased care on the part of the defendant are likely to (stochastically) reduce the likelihood of harm (that is, shift $\mathrm{F}$ to the left), thereby lowering the expected number of cases filed and, consequently, the number of trials.

A reduction in the number of trials contributes to social efficiency and, as indicated above, this will hold for one of the regimes, even if we account for the cases that would be brought under PBLD but not under IBLD and for the effects of increased care. However, a further factor in assessing relative efficiency bears mentioning, but is beyond the scope of this paper: does PBLD's effect on D's payoff (see Proposition 8) redress a problem because deterrence incentives are insufficient under IBLD, or does it lead to over-deterrence if (instead) deterrence incentives are sufficient under IBLD? This also affects a final judgment as to the social value of PBLD, which we leave to future research.

${ }^{29}$ Here, the "particulars" of the F distribution is the mean; in the extended model of liability determination in the Appendix, it is the expected value of the inverse of the function describing the relationship between the percentage of exposed users harmed and the probability of liability. 


\section{Robustness Considerations}

We now consider two modifications of the analysis above so as to show that our results are likely to hold for many conceivable bargaining scenarios and for a variety of ways of translating a population effect (such as heretofore represented by $\alpha$ ) into the probability of liability that P, PA, and $\mathrm{D}$ will adopt in their settlement bargaining. The first modification is to reverse the roles of who makes a take-it-or-leave-it offer to whom; below we analyze the signaling-game analog to the screening games in Sections 3 and 4. No results are reversed, though many of the differences between IBLD and PBLD disappear; nevertheless the joint payoff to $\mathrm{P}$ and PA is still higher under PBLD than under IBLD. This means that the differences in incentives to file carry over to the signaling model, as does the direction of incentives for care-taking by $\mathrm{D}$. Thus, to the degree that one imagines settlement bargaining to be better represented by, say, a random-proposer model (in an attempt to balance the opportunities to make a first move), the resulting effects will all go in the same direction as described in the propositions, though there may be some muting of these effects in the bargaining subgame.

The second modification below generalizes the model of PBLD we employed in Section 4, relaxing the assumption that $\alpha$ represents both the fraction of users who are harmed and the probability of liability of the defendant. The second sub-section below and the Appendix provide a modified screening analysis that shows that more sophisticated models of how $\alpha$ influences liability still have the same qualitative results indicated in our analysis of the PBLD regime and in the comparison with the results of the analysis of the IBLD regime.

Reversing Timing in the Settlement Game: Signaling Instead of Screening

In the previous sections we assume that the uninformed party $\mathrm{P}$ (and her attorney $\mathrm{PA}$ ) make 
a settlement demand of the informed $\mathrm{D}$, resulting in a screening model. Alternatively, if the informed party D were to make a settlement offer to P and PA, then the offer might reveal D's true type $\alpha$; that is, there may be a separating equilibrium in a signaling game. We now characterize such a separating equilibrium for the bargaining subgame, and trace its implications for the overall game. $^{30}$

We continue to assume that $\mathrm{P}$ has the ultimate authority to decide whether the case goes to trial following failed settlement negotiations. Since P will pay PA only a share of her court award, this means that $\mathrm{P}$ always has a credible threat to take the case to trial (following failed negotiations). However, we assume that P and PA jointly decide whether to accept or reject D's offer (much as they jointly determined their settlement demand in the screening model).

In the Appendix we show that D's offer function is $\mathrm{s}^{*}(\alpha)=\alpha \delta-\mathrm{c}_{\mathrm{P}}$ for $\alpha \in[0,1]$, and that $\mathrm{P}$ and PA randomize between accepting and rejecting D's offer, with higher offers being progressively less likely to be rejected. As can be seen in the equilibrium derived in the Appendix, the distribution of $\alpha$ is not relevant; only the support $[0,1]$, which is common to $G$ and $F$. This is a standard feature of separating equilibria in signaling models.

Thus, for the settlement bargaining subgame, it is immaterial whether P and PA use the distribution F or the distribution G. However, in deciding whether to file suit, this distinction will matter. Since P and PA are only able to accept or reject D's offer, they are pushed to indifference and hence receive a payoff of $t \delta-c_{P}$ when facing a defendant of type $t$, regardless of whether they settle or go to trial. The ex ante expected combined payoff to $\mathrm{P}$ and $\mathrm{PA}$ is thus given by $\mathrm{V}(\mathrm{F}) \equiv$

${ }^{30}$ We present only a summary of the analysis here and in the Appendix; for details on how to solve such a model, see Reinganum and Wilde (1986). 
$\mathrm{E}_{\mathrm{F}}\left\{\mathrm{t} \delta-\mathrm{c}_{\mathrm{P}}\right\}=\mu_{\mathrm{F}} \delta-\mathrm{c}_{\mathrm{P}}$ for the IBLD model and by $\mathrm{V}(\mathrm{G}) \equiv \mathrm{E}_{\mathrm{G}}\left\{\mathrm{t} \delta-\mathrm{c}_{\mathrm{P}}\right\}=\mu_{\mathrm{G}} \delta-\mathrm{c}_{\mathrm{P}}$ for the PBLD model. It is clear that $\mathrm{V}(\mathrm{G})>\mathrm{V}(\mathrm{F})$ since $\mu_{\mathrm{G}}>\mu_{\mathrm{F}}$.

Finally, to examine the filing decision we again indicate the equilibrium payoffs' dependence on $\delta$ and incorporate the filing costs $\mathrm{K}$ to obtain $\mathrm{V}(\mathrm{F} ; \delta)-\mathrm{K}$ and $\mathrm{V}(\mathrm{G} ; \delta)$ - $\mathrm{K}$. For any given $\mathrm{K}$, a suit will be filed for $\delta \in\left[\delta_{F}, \infty\right)$ for the IBLD model and for $\delta \in\left[\delta_{\mathrm{G}}, \infty\right)$ for the PBLD model, where $\delta_{\mathrm{G}}$ $<\delta_{\mathrm{F}}{ }^{31}$ Alternatively, for any given $\delta$, a suit will be filed for $\mathrm{K} \in\left[0, \mathrm{~K}_{\mathrm{F}}\right]$ for the IBLD model and for $\mathrm{K} \in\left[0, \mathrm{~K}_{\mathrm{G}}\right]$ for the PBLD model, where $\mathrm{K}_{\mathrm{G}}>\mathrm{K}_{\mathrm{F}}$. Thus, although the IBLD and PBLD models yield exactly the same equilibrium behavior and payoffs in the settlement negotiation subgame, $\mathrm{P}$ and PA have a higher ex ante expectation of recovery in the PBLD model and hence will have a higher propensity to file suit; that is, propositions analogous to Propositions 6, 7, and 8 hold.

\section{A More General Model Linking the Fraction of Users Harmed to the Likelihood of Liability}

In the PBLD model in Section 4, we assume that the probability that the defendant will be found liable is given by $\alpha$, the fraction of users harmed. A more general model would allow liability, $\ell$, to be a function $\mathrm{L}$ of $\alpha: \ell \equiv \mathrm{L}(\alpha){ }^{32}$ In the Appendix we discuss generalizations that involve modeling this probability of liability as a differentiable and increasing function of $\alpha$. To understand what type of models we have in mind, suppose that we use the square root of $\alpha$ as our representation of liability (instead of $\alpha$ ). Then instead of, say, an observation that $25 \%$ of the users being harmed implied a 0.25 probability of $\mathrm{D}$ being found liable, now the observation that $25 \%$ of the users are harmed implies a 0.5 probability of $\mathrm{D}$ being found liable, since $0.5=(0.25)^{1 / 2}$.

${ }^{31}$ Note that we are using the same notation for the cut-offs as used earlier; the actual values of the cut-offs will differ between the screening and the signaling models.

${ }^{32}$ A special case is $\mathrm{L}(\alpha)=\alpha$, giving the results in Section 4 . 
Figure 5 illustrates two examples of possible liability functions; in each panel the liability function used in Sections 4 and 5 above is shown as the dashed line, while the solid line shows a non-linear example. For example, Figure 5(a) illustrates $L(\alpha)$ for a case such as the square root of $\alpha$ representation just discussed. On the other hand, Figure 5(b) illustrates $L(\alpha)$ as a "soft" threshold function. Such a function might arise from a building consensus about a level of relative risk that supports a finding of general causation. ${ }^{33}$

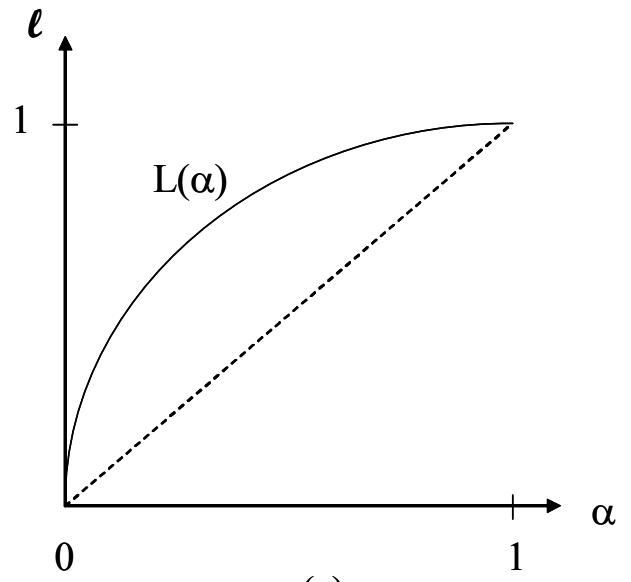

(a)

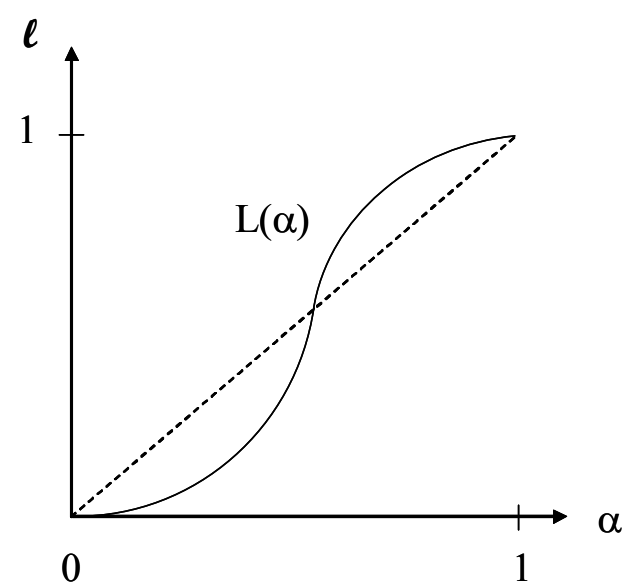

(b)

Figure 5: Two Examples of $\mathrm{L}(\alpha)$

The purpose of the material in the Appendix is to show that employing any differentiable, increasing function $\mathrm{L}(\alpha)$ makes no real change in the analysis, since versions of Propositions 2 through 8 (the ones concerned with the PBLD model or the PBLD versus IBLD comparisons) still hold, albeit with quantitative adjustments made to the posterior distribution of $\ell$ reflecting any specific differentiable and increasing function $L(\alpha)$.

${ }^{33}$ See Green (2000). As discussed therein, a relative risk of 2 suggests that the source under scrutiny raises the risk of harm to twice that attributable to other sources; this is viewed by some as indicating a meeting of a preponderance-of-the-evidence standard. Thus, if $\alpha_{0}$ is the background risk and a relative risk of (approximately) 2 is required, then $\mathrm{L}(\alpha)$ should be sharply increasing in the neighborhood of $\alpha=2 \alpha_{0}$. This would produce the "soft" threshold model displayed. 
7. Summary, Some Broader Implications, and Possible Extensions

\section{Summary}

Modern real-world cases are likely to involve a mix of individual-based and populationbased aspects in overall liability determination; many mass tort cases are likely to involve PBLD elements. In this paper we have modeled liability as being wholly of one form or the other, so as to understand the incentives that each produces. For the same reason, we abstracted from any consideration of class actions in our analysis (but see below). Holding all else constant, in contrast with individual-based liability determination, population-based liability determination creates increased incentives for the plaintiff and her attorney to bring a case by increasing their ex ante joint expected payoff, and results in an increased settlement demand made of the defendant. Consequently, the defendant in a PBLD case faces an increased ex ante expected cost compared with the IBLD regime, thereby increasing incentives to take care.

Based on the prior distribution of actual harms, $\mathrm{F}(\bullet)$, it might appear to an outsider that in certain types of cases plaintiffs are overly-litigious, since they may file suit more often and make higher settlement demands than would be predicted based on $\mathrm{F}(\bullet) \cdot{ }^{34}$ This might be interpreted as plaintiffs having an optimism bias. However, if population-based evidence will be used to establish liability, then it is completely rational for the plaintiff to use the (upward-revised) posterior distribution $\mathrm{G}(\bullet)$ in her decision-making.

Under PBLD, the plaintiff's demand will never act to pool the types of defendant, meaning

34 An "outsider" here might be interpreted as someone who has never been exposed to the source of harm that is involved in the litigation. This perception would be even stronger if the outsider was exposed but not harmed, since this person would have a downward-revised posterior distribution over $\alpha$; see footnote 7 . 
that there is always a positive likelihood of trials under PBLD (even if the IBLD demand would involve pooling and hence, no trials). However, PBLD need not always imply an increased likelihood of trial relative to IBLD for any filed case (though it may lead to more cases being filed); the heightened aggressiveness of the plaintiff and her attorney can actually lead to a reduction in the likelihood of trial. Thus, PBLD can be more, or less, efficient than IBLD (in the sense of reducing trial costs), when considering cases that would be filed in both possible regimes.

In Section 6 we extended our analysis to verify the robustness of our findings. First, we recast the bargaining model as a signaling game wherein the defendant made an offer to the plaintiff and her attorney. While some of the differences between the IBLD and PBLD results derived under a screening analysis disappeared, no results were reversed and the essential predictions concerning how PBLD increases the stakes for all parties remained. Therefore, any random proposer model would inherit all the qualitative results of our analysis in Sections 4 and 5. Second, we examined a broad generalization of our basic model of how population considerations translate into liability assessments. We showed that all our results in Sections 4 and 5 continue to hold, though they are modified to reflect the more general transformation of the fraction of the users who are harmed into the probability of liability.

Thus, the overall picture that emerges is one wherein settlement negotiation in cases that have both IBLD and PBLD elements (for example, IBLD causation but PBLD fault, or vice versa) will inherit properties from the mixing of the two models, and thus are likely to reflect (to some degree) a bargaining externality due to the reference to population-based arguments in the negotiations and possible subsequent trial. As such, this paper is also a contribution to the literature on settlement with externalities that has developed, with previous applications to the formation of 
class actions, analyses of joint and several liability, insolvency, confidential settlement, and the use of most-favored-nations clauses in settlement agreements. ${ }^{35}$ Here PBLD induces a positive externality because there is settlement negotiation "in the shadow of other related harms."

\section{Some Broader Implications}

Our overall results lead to some broader implications, which we now consider. We have assumed that the costs of trial are fixed. While one effect of the increased ex ante stakes for all parties is increased incentives for care, another effect is that the increased stakes are likely to translate into increased incentives to spend resources on trials. ${ }^{36}$ For example, the use of PBLD in settings involving epidemiological modeling of general causation is a good example of this effect, as considerable resources appear to be spent on producing, and attacking, expert witnesses. Such an increase in the costs of trial will feed back to moderate the incentive to file suit. Along the same line is the incentive for the potential defendant to suppress information that might be of use to a plaintiff; this appeared to be the case in Manko discussed earlier, and has been asserted in a number of other controversial cases. To the degree that effective discovery processes can document this (or, as in Manko, that a court will formally recognize such behavior and adjust for it), this may or may not create a long-run inefficiency.

The increased stakes result does suggest, however, another incentive: to the degree that PBLD reflects science that is incomplete (in the sense of documenting and understanding cause-andeffect relationships), one way for a potential defendant to reduce future possible litigation costs is

35 See Daughety and Reinganum (2005) and Spier (forthcoming) for surveys of this developing literature.

36 For a model wherein evidence costs are endogenously-determined, see Daughety and Reinganum (2000b). 
to invest in improving the science of harm associated with the product. This has two effects: it should lead to better-designed products (producing a leftward shift of F, and therefore of G) since firms may learn how to obtain the benefits with a lower likelihood of harm, and it might result in a shift of liability determination from PBLD toward IBLD, thereby shifting a potential plaintiff's analysis toward use of $\mathrm{F}$ rather than $\mathrm{G}$.

Finally, we would note that PBLD enhances the incentives for bringing valid cases that would fail to be brought under IBLD. This figures not only into cases involving issues of complex causation, but also into issues of fault; the settlements cited in Section 2 involving the Catholic Church in cases of child abuse by priests are an example here. As we discussed in our footnote concerning filing costs, in some cases such costs include the disutility of filing, something that was undoubtedly significant for some of those victims and might have deterred some valid cases. In these circumstances PBLD is likely to generate a distinct social benefit.

\section{Possible Extensions: PBLD and the Incentives to Form a Class}

In this paper we have focused on the underlying incentives for suit and settlement that arise simply because part or all of the liability determination process depends on population-based information. This creates a rational basis on the part of the victim and her attorney to update their assessment of the defendant's likelihood of being found liable in a direction that encourages a form of aggressiveness reflected in higher settlement demands, and an increased incentive for an individual to file suit, under PBLD than under IBLD.

This reflects the core positive externality aspect of PBLD, but one could imagine a yet stronger incentive created by PBLD, under a suitable extension of the basic model developed in Section 4. What if the plaintiff's side also updates on the fact that other victims have also filed suit? 
Under PBLD, this would potentially further enhance the value of suit, and it also has the potential to encourage class formation (for example, so as to improve the statistical analysis that would be used in showing general causation, or to distill pattern-of-behavior similarities in asserting and proving fault).

Therefore, our model of PBLD could be used to develop a dynamic model of class formation. Notice that such a dynamic process could generate a "bank run" phenomenon (here on a defendant corporation rather than a bank) if individual claimants and their attorneys (upon observing the rising collection of lawsuits) fear that the defendant's solvency might be at risk, thereby initiating a race in an attempt to establish the priority of their claims (or a least a viable stake in being part of an early settlement).

Thus, a further spinoff would be to understand the conditions under which it is socially beneficial to allow class actions, whether the drivers are cost efficiencies so that individual meritorious, but negative-expected value, suits could be aggregated and adjudicated, or whether the only way to acquire the information needed is through using the aggregate class characteristics to distill the likelihood of the defendant's actions being the important source of the harm the plaintiffs have borne. As an illustration of this point, consider a recent lawsuit against the tobacco industry charging that the marketing of "light" cigarettes was a fraud, as smokers who bought the cigarettes were told via advertising that such cigarettes were safer than regular cigarettes, when (it is alleged) they were not and the tobacco companies knew this. This suit has been certified as a class, ${ }^{37}$ partly in order to ascertain the fraction of such smokers who would not have purchased light cigarettes at

${ }^{37}$ Schwab v. Philip Morris, 449 F. Supp. 2 d 992 (ED NY, 2006); at this writing, the district court's decision to certify the class is on appeal to the $2^{\text {nd }}$ Circuit. The stakes here are significant because this case is filed as a RICO case, which allows for treble damages. 
the prevailing price but for the defendants' (allegedly) fraudulent claims. Such information will then contribute to a jury's assessment of the industry's liability. In Schwab v. Philip Morris, Judge Weinstein indicates this as one of the reasons for certifying the class:

"In the American legal system, whose watchword has been, as already noted, 'no right without a remedy,' the answer is that modern civil procedure, scientific analysis, and the law of large numbers used by statisticians provide a legal basis for a practical and effective remedy. The plaintiffs are entitled to the chance to prove their allegations." ${ }^{38}$

Our fundamental point remains that it is the nature of the harms incurred, and the relevant available means for demonstrating cause and/or fault (such as direct tracing in some cases, but statistical analysis of causality and risk in others), that shifts liability determination between the two basic schemes of IBLD and PBLD. Then the incentives engendered may (in either case) lead to individual actions or class actions.

${ }^{38}$ Schwab v. Philip Morris, p. 1022. 
Appendix

Proof of Proposition 1. The derivative of the joint payoff is: $Z^{\prime}(\lambda ; F)=\delta(1-F(\lambda))-\operatorname{Cf}(\lambda)$. Thus $\operatorname{sgn}\left(Z^{\prime}(\lambda ; F)\right)=\operatorname{sgn}(\delta / C-f(\lambda) /(1-F(\lambda)))$. Since $f(0)<\delta / C$, it follows that $Z^{\prime}(0 ; F)>0$; moreover, $\lim _{\lambda \rightarrow 1} Z^{\prime}(\lambda ; F)<0$ since $f(\lambda) /(1-F(\lambda))$ goes to infinity as $\lambda$ goes to 1 . Finally, the expression $\delta / C-$ $f(\lambda) /(1-F(\lambda))$ changes sign only once (since the hazard rate is strictly increasing). Thus, the function $\mathrm{Z}(\lambda ; F)$ is single-peaked in $\lambda$ and reaches its peak at the unique value $\lambda^{*}$ that satisfies $Z^{\prime}\left(\lambda^{*} ; F\right)=0$ or, equivalently, $f\left(\lambda^{*}\right) /\left(1-F\left(\lambda^{*}\right)\right)=\delta / C$. QED.

Proof of Proposition 2. By definition (Mas-Collel, Whinston and Green, 1995, p. 195), G(•) FOSD $\mathrm{F}(\bullet)$ if and only if $\mathrm{G}(\alpha) \leq \mathrm{F}(\alpha)$ for all $\alpha \in[0,1]$ (with $\mathrm{G}(\alpha)<\mathrm{F}(\alpha)$ on a set of positive measure). Applying integration by parts to the expression $\mathrm{G}(\alpha)=\int_{0}^{\alpha} \mathrm{tf}(\mathrm{t}) \mathrm{dt} / \mu_{\mathrm{F}}$ yields:

$$
\mathrm{G}(\alpha)=\left(1 / \mu_{\mathrm{F}}\right)\left[\alpha \mathrm{F}(\alpha)-\int_{0}^{\alpha} \mathrm{F}(\mathrm{t}) \mathrm{dt}\right] .
$$

Then $\mathrm{G}(\alpha) \leq \mathrm{F}(\alpha)$ if and only if $\left(1 / \mu_{\mathrm{F}}\right)\left[\alpha \mathrm{F}(\alpha)-\int_{0}^{\alpha} \mathrm{F}(\mathrm{t}) \mathrm{dt}\right] \leq \mathrm{F}(\alpha)$; that is, if and only if $\Delta(\alpha) \equiv(\alpha-$ $\left.\mu_{\mathrm{F}}\right) \mathrm{F}(\alpha)-\int_{0}^{\alpha} \mathrm{F}(\mathrm{t}) \mathrm{dt} \leq 0$. It is clear that $\Delta(\alpha)<0$ for all $\alpha \leq \mu_{\mathrm{F}}$. For $\alpha>\mu_{\mathrm{F}}$, the function $\Delta(\alpha)$ is increasing since $\Delta^{\prime}(\alpha)=\left(\alpha-\mu_{\mathrm{F}}\right) \mathrm{f}(\alpha)$. Moreover, $\Delta(1)=1-\mu_{\mathrm{F}}-\int_{0}^{1} \mathrm{~F}(\mathrm{t}) \mathrm{dt}=0$. Therefore, $\mathrm{G}(\alpha)<$ $F(\alpha)$ for all $\alpha \in(0,1)$, while $\mathrm{G}(0)=\mathrm{F}(0)$ and $\mathrm{G}(1)=\mathrm{F}(1)$, and thus $\mathrm{G}(\bullet) \mathrm{FOSD} F(\bullet)$. To see that this implies $\mu_{\mathrm{G}}>\mu_{\mathrm{F}}$, simply note that $\mu_{\mathrm{G}}-\mu_{\mathrm{F}}=1-\int_{0}^{1} \mathrm{G}(\mathrm{t}) \mathrm{dt}-\left[1-\int_{0}^{1} \mathrm{~F}(\mathrm{t}) \mathrm{dt}\right]=\int_{0}^{1}[\mathrm{~F}(\mathrm{t})-\mathrm{G}(\mathrm{t})] \mathrm{dt}>0$. QED.

Proof of Proposition 3. The derivative of the joint payoff is: $Z^{\prime}(\alpha ; G)=\delta[1-G(\alpha)]-\operatorname{Cg}(\alpha)$. Thus $\operatorname{sgn}\left(Z^{\prime}(\alpha ; G)\right)=\operatorname{sgn}(\delta / C-g(\alpha) /(1-G(\alpha)))$. Since $g(0)=0<\delta / C$, it follows that $Z^{\prime}(0 ; G)>0$; moreover, $\lim _{\alpha \rightarrow 1} Z^{\prime}(\alpha ; G)<0$ since $g(\alpha) /(1-G(\alpha))=\alpha f(\alpha) /\left[\mu_{F}-\alpha F(\alpha)+\int_{0}^{\alpha} F(t) d t\right]$ goes to infinity 
as $\alpha$ goes to 1 . Thus, the function $Z(\alpha ; G)$ is first increasing and eventually decreasing; that is, there exists at least one $\alpha^{*} \in(0,1)$ that is a maximizer of $Z(\alpha ; G)$; moreover $\alpha^{*}$ satisfies $g\left(\alpha^{*}\right) /\left(1-G\left(\alpha^{*}\right)\right)$ $=\delta / C$. QED.

Proof of Proposition 4. $g(\alpha) /(1-\mathrm{G}(\alpha))=\alpha \mathrm{f}(\alpha) /\left[\mu_{\mathrm{F}}-\alpha \mathrm{F}(\alpha)+\int_{0}^{\alpha} \mathrm{F}(\mathrm{t}) \mathrm{dt}\right]<\mathrm{f}(\alpha) /(1-\mathrm{F}(\alpha))$ if and only if $\Phi(\alpha) \equiv \alpha-\mu_{\mathrm{F}}-\int_{0}^{\alpha} \mathrm{F}(\mathrm{t}) \mathrm{dt} \leq 0$. It is clear that $\Phi(\alpha)<0$ for all $\alpha \leq \mu_{\mathrm{F}}$. For $\alpha>\mu_{\mathrm{F}}$, the function $\Phi(\alpha)$ is increasing since $\Phi^{\prime}(\alpha)=1-\mathrm{F}(\alpha)$. Moreover, $\Phi(1)=1-\mu_{\mathrm{F}}-\int_{0}^{1} \mathrm{~F}(\mathrm{t}) \mathrm{dt}=0$. Therefore, $\mathrm{g}(\alpha) /(1-$ $\mathrm{G}(\alpha))<\mathrm{f}(\alpha) /(1-\mathrm{F}(\alpha))$ for all $\alpha \in[0,1)$. QED.

Proof of Proposition 5. Recall that $\alpha^{*}$ maximizes $Z(\alpha ; G)$ and thus satisfies $g\left(\alpha^{*}\right) /\left(1-\mathrm{G}\left(\alpha^{*}\right)\right)=\delta / \mathrm{C}$, while $\lambda^{*}$ maximizes $Z(\lambda ; F)$ and thus satisfies $f\left(\lambda^{*}\right) /\left(1-F\left(\lambda^{*}\right)\right)=\delta / C$. But then $f\left(\lambda^{*}\right) /\left(1-F\left(\lambda^{*}\right)\right)=$ $\delta / \mathrm{C}=\mathrm{g}\left(\alpha^{*}\right) /\left(1-\mathrm{G}\left(\alpha^{*}\right)\right)<\mathrm{f}\left(\alpha^{*}\right) /\left(1-\mathrm{F}\left(\alpha^{*}\right)\right)$, where the last inequality follows from Proposition 4. Since the hazard rate $f(\bullet) /(1-F(\bullet))$ is strictly increasing, it follows that $\alpha^{*}>\lambda^{*}$. QED.

Proof of Proposition 6. In the IBLD model, the combined payoff to P and PA conditional on a defendant of type $t$ can be written as $z\left(t ; \lambda^{*}\right)=t \delta-c_{P}$ if $t \leq \lambda^{*}$ and $z\left(t ; \lambda^{*}\right)=\lambda^{*} \delta+c_{D}$ if $t>\lambda^{*}$; notice that $\mathrm{z}(\mathrm{t} ; \lambda)$ is a non-decreasing function of $\mathrm{t}$, with portions that are strictly increasing if $\lambda^{*}>0$. Moreover, the expected combined payoff to $\mathrm{P}$ and PA in the IBLD model is given by $\mathrm{Z}\left(\lambda^{*} ; \mathrm{F}\right)=$ $\mathrm{E}_{\mathrm{F}}\left\{\mathrm{z}\left(\mathrm{t} ; \lambda^{*}\right)\right\}$. Also, define $\mathrm{Z}\left(\lambda^{*} ; \mathrm{G}\right) \equiv \mathrm{E}_{\mathrm{G}}\left\{\mathrm{Z}\left(\mathrm{t} ; \lambda^{*}\right)\right\}$. Since $\mathrm{G}(\bullet) \operatorname{FOSD} \mathrm{F}(\bullet), \mathrm{Z}\left(\lambda^{*} ; \mathrm{G}\right) \geq \mathrm{Z}\left(\lambda^{*} ; \mathrm{F}\right)$ because $z\left(t ; \lambda^{*}\right)$ is a non-decreasing function of $t$. First, assume that $\lambda^{*}>0$. Since $z\left(t ; \lambda^{*}\right)$ is strictly increasing on a sub-interval, then using integration by parts yields $Z\left(\lambda^{*} ; G\right)-Z\left(\lambda^{*} ; F\right)=$ $\int_{0}^{1} z^{\prime}\left(t ; \lambda^{*}\right)[F(t)-G(t)] d t>0$, where $z^{\prime}\left(t ; \lambda^{*}\right)$ is the derivative of $z\left(t ; \lambda^{*}\right)$ and $F(t)>G(t)$ for $t \in(0,1)$. 
If $\lambda^{*}=0$, then $Z\left(\lambda^{*} ; G\right)=Z\left(\lambda^{*} ; F\right)$. In either case, note that $Z\left(\alpha^{*} ; G\right)>Z\left(\lambda^{*} ; G\right)$ because $\alpha^{*}$ maximizes $Z(\alpha ; G)$, while $\lambda^{*}$ does not. Combining these two inequalities yields $Z\left(\alpha^{*} ; G\right)>Z\left(\lambda^{*}\right.$; F). QED.

Proof of Proposition 7. First, note that $\mathrm{K}_{\mathrm{G}} \equiv \mathrm{Z}\left(\alpha^{*} ; \mathrm{G}, \delta\right)>\mathrm{Z}\left(\lambda^{*} ; \mathrm{F}, \delta\right) \equiv \mathrm{K}_{\mathrm{F}}$, where the inequality follows from Proposition 6. Second, inspection of the payoff functions $Z\left(\lambda^{*} ; F, \delta\right)$ and $Z\left(\alpha^{*} ; G, \delta\right)$ and application of the envelope theorem implies that both are increasing functions of $\delta$. If $\mathrm{Z}\left(\lambda^{*} ; \mathrm{F}, \underline{\delta}\right)-\mathrm{K} \geq 0$, then $\delta_{\mathrm{G}}=\delta_{\mathrm{F}}=\underline{\delta}$. If $\mathrm{Z}\left(\lambda^{*} ; \mathrm{F}, \underline{\delta}\right)-\mathrm{K}<0$, then since $\mathrm{Z}\left(\alpha^{*} ; \mathrm{G}, \delta_{\mathrm{F}}\right)-\mathrm{K}>\mathrm{Z}\left(\lambda^{*} ; \mathrm{F}, \delta_{\mathrm{F}}\right)$ - K $=0$, it follows that $\delta_{\mathrm{G}}<\delta_{\mathrm{F}}$. QED.

Proof of Proposition 8. Conditional on a suit being filed, the defendant's payoff if he is of type $t$ is given by $\mathrm{w}\left(\mathrm{t} ; \lambda^{*}\right)=\mathrm{t} \delta+\mathrm{c}_{\mathrm{D}}$ if $\mathrm{t}<\lambda^{*}$ and $\mathrm{w}\left(\mathrm{t} ; \lambda^{*}\right)=\lambda^{*} \delta+\mathrm{c}_{\mathrm{D}}$ if $\mathrm{t} \geq \lambda^{*}$ for the IBLD model, and as $\mathrm{w}\left(\mathrm{t} ; \alpha^{*}\right)=\mathrm{t} \delta+\mathrm{c}_{\mathrm{D}}$ if $\mathrm{t}<\alpha^{*}$ and $\mathrm{w}\left(\mathrm{t} ; \alpha^{*}\right)=\alpha^{*} \delta+\mathrm{c}_{\mathrm{D}}$ if $\mathrm{t} \geq \alpha^{*}$ for the PBLD model. Since $\alpha^{*}>\lambda^{*}$, it follows that $\mathrm{w}\left(\mathrm{t} ; \alpha^{*}\right)=\mathrm{w}\left(\mathrm{t} ; \lambda^{*}\right)$ for $\mathrm{t} \leq \lambda^{*}$ and $\mathrm{w}\left(\mathrm{t} ; \alpha^{*}\right)>\mathrm{w}\left(\mathrm{t} ; \lambda^{*}\right)$ for $\mathrm{t}>\lambda^{*}$. The last claim follows directly from Proposition 5. QED.

$\underline{\text { Signaling Model of Settlement Bargaining Under IBLD and PBLD }}$

$\mathrm{P}$ and PA will accept a settlement offer of $s$ if and only if $\mathrm{s} \geq \mathrm{b}(\mathrm{s}) \delta-\mathrm{c}_{\mathrm{P}}$, where $\mathrm{b}(\mathrm{s})$ represents the belief of $\mathrm{P}$ (and PA) about $\alpha$, based on the settlement offered. In a separating equilibrium, $\mathrm{P}$ and PA will randomize between accepting and rejecting D's offer; thus a strategy for P and PA is a probability of rejection function, denoted $\mathrm{r}(\mathrm{s})$. Let $\left(\mathrm{s}^{*}(\alpha), \mathrm{r}^{*}(\mathrm{~s}), \mathrm{b}^{*}(\mathrm{~s})\right)$ be the strategies and beliefs in a separating perfect Bayesian equilibrium. Then it must be that: $(1) \mathrm{s}^{*}(\alpha)$ minimizes D's expected 
payment $\mathrm{s}(1-\mathrm{r}(\mathrm{s}))+\mathrm{r}(\mathrm{s})\left(\alpha \delta+\mathrm{c}_{\mathrm{D}}\right)$; (2) P and PA must be willing to randomize between acceptance and rejection; and (3) the beliefs $b^{*}(s)$ must be correct; that is, $b^{*}\left(s^{*}(\alpha)\right)=\alpha$.

Differentiating D's expected payoff yields the first-order-condition $1-r(s)+r^{\prime}(s)\left(\alpha \delta+c_{D}-\right.$ $\mathrm{s})=0$. Given consistent beliefs, P and PA will only be willing to randomize if $\mathrm{s}^{*}(\alpha)=\alpha \delta-\mathrm{c}_{\mathrm{P}}$. Substituting this into the first-order condition yields a differential equation for $r^{*}(s): 1-r(s)+r^{\prime}(s) C$ $=0$. Solving this equation and applying the boundary condition that the highest equilibrium offer $\delta-\mathrm{c}_{\mathrm{P}}$ will never be rejected yields the solution $\mathrm{r}^{*}(\mathrm{~s})=1-\exp \left\{-\left(\delta-\mathrm{c}_{\mathrm{P}}-\mathrm{s}\right) / \mathrm{C}\right\}$ for $\mathrm{s} \in\left[-\mathrm{c}_{\mathrm{P}}, \delta-\mathrm{c}_{\mathrm{P}}\right]^{39}$ D's offer function is $\mathrm{s}^{*}(\alpha)=\alpha \delta-\mathrm{c}_{\mathrm{P}}$ for $\alpha \in[0,1]$, and the consistent beliefs are $\mathrm{b}^{*}(\mathrm{~s})=\left(\mathrm{s}+\mathrm{c}_{\mathrm{P}}\right) / \delta$.

\section{Generalization of the Probability of Liability Function}

Let $\ell$ denote the probability that the defendant will be held liable, and suppose that $\ell$ is given by $\mathrm{L}(\alpha)$, where $\mathrm{L}(\bullet)$ is a differentiable and strictly increasing function with $\mathrm{L}(0)=0$ and $\mathrm{L}(1)=1$. For future reference, let $h(\ell) \equiv \mathrm{L}^{-1}(\ell)$; then $\mathrm{h}(\ell)$ is also differentiable and strictly increasing with $\mathrm{h}(0)$ $=0$ and $\mathrm{h}(1)=1$.

To maintain comparability with the IBLD model, we assume that $\ell$ is distributed according to $\mathrm{F}(\bullet)$ on $[0,1]$. We are interested in deriving $\mathrm{g}(\ell)$, which is the probability (density) of $\ell$, given that $\mathrm{P}$ has been harmed. To calculate this using Bayes' Rule, we need $\operatorname{Pr}\{\mathrm{P}$ is harmed $\mid \ell\}$. As before, $\operatorname{Pr}\{\mathrm{P}$ is harmed $\mid \alpha\}=\alpha$; conditional on $\ell$, the associated value of $\alpha$ is given by $h(\ell)$, and therefore $\operatorname{Pr}\{\mathrm{P}$ is harmed $\mid \ell\}=\mathrm{h}(\ell)$. This yields: $\mathrm{g}(\ell)=\mathrm{h}(\ell) \mathrm{f}(\ell) / \mathrm{T}_{\mathrm{F}}$, where $\mathrm{T}_{\mathrm{F}} \equiv \int_{0}^{1} \mathrm{~h}(\mathrm{t}) \mathrm{f}(\mathrm{t}) \mathrm{dt}$. For future

39 Recall that $\mathrm{P}$ has the ultimate authority to choose to proceed to trial. It is a bit odd that $\mathrm{P}$ and PA might accept a negative offer but, given that $\mathrm{P}$ will always want to forge ahead with trial following a rejection, the combined payoff of $\mathrm{P}$ and $\mathrm{PA}$ will involve paying $\mathrm{c}_{\mathrm{P}}$ if settlement negotiations fail, so they will be willing to accept a negative payoff if the defendant turns out to have a very low value of $\alpha$. 
reference note that, by construction, $0=\int_{0}^{1}\left[\mathrm{~h}(\mathrm{t})-\mathrm{T}_{\mathrm{F}}\right] \mathrm{f}(\mathrm{t}) \mathrm{dt}$. Since $\mathrm{h}$ is strictly increasing with $\mathrm{h}(0)$ $=0$ and $\mathrm{h}(1)=1$, it follows that there exists a unique value $\ell_{\mathrm{m}} \in(0,1)$ such that $\mathrm{h}(\ell)(<=>) \mathrm{T}_{\mathrm{F}}$ as $\ell$ $(<=>) \ell_{\mathrm{m}}$. Finally, we can write $\mathrm{G}(\ell)=\int_{0}^{\ell} \mathrm{h}(\mathrm{t}) \mathrm{f}(\mathrm{t}) \mathrm{dt} / \mathrm{T}_{\mathrm{F}}$. Notice that this G-distribution is not the same as the one derived in Section 4, due to the transformation $\ell=\mathrm{L}(\alpha)$. Nevertheless, it shares all the properties derived for the G-distribution in Sections 4 and 5.

Proposition 2'. G first-order stochastic dominates F.

Proof. Recall that the distribution G FOSD the distribution $F$ if $G(\ell) \leq F(\ell)$ for all $\ell$, with a strict inequality on at least a subset of $[0,1]$. First note that $\mathrm{G}(0)=\mathrm{F}(0)=0$ and $\mathrm{G}(1)=\mathrm{F}(1)=1$, since both are probability distributions. We now show that $\mathrm{G}(\ell)<\mathrm{F}(\ell)$ for $\ell \in(0,1)$, and therefore $\mathrm{G}$ FOSD F. To see this, observe that $\mathrm{G}(\ell)<\mathrm{F}(\ell)$ if and only if $\Delta(\ell) \equiv \int_{0}^{\ell} \mathrm{h}(\mathrm{t}) \mathrm{f}(\mathrm{t}) \mathrm{dt}-\mathrm{T}_{\mathrm{F}} \mathrm{F}(\ell)<0$. It is clear that $\Delta(0)=0$ and $\Delta(1)=0$. Differentiation yields $\Delta^{\prime}(\ell)=\left[\mathrm{h}(\ell)-\mathrm{T}_{\mathrm{F}}\right] \mathrm{f}(\ell)(<=>) 0$ as $\ell(<=>)$ $\ell_{\mathrm{m}}$. Thus $\Delta(\ell)$ starts at 0 , declines to a minimum at $\ell_{\mathrm{m}}$, and then rises back to 0 , establishing that $\Delta(\ell)$ $<0$ for $\ell \in(0,1)$. QED.

Proposition 4'. Both hazard rates go to infinity as $\ell$ goes to 1 ; otherwise, $g(\ell) /(1-\mathrm{G}(\ell))<\mathrm{f}(\ell) /(1-$ $F(\ell))$ for all $\ell \in[0,1)$.

Proof. Recall that $g(\ell)=h(\ell) f(\ell) / T_{F}$. Since both $h(\ell)$ and $f(\ell)$ are bounded, while $G(1)=F(1)=1$, both hazard rates go to infinity as $\ell$ goes to 1 . To verify the second claim, note that $g(\ell) /(1-G(\ell))$ $=\mathrm{h}(\ell) \mathrm{f}(\ell) /\left[\mathrm{T}_{\mathrm{F}}-\int_{0}^{\ell} \mathrm{h}(\mathrm{t}) \mathrm{f}(\mathrm{t}) \mathrm{dt}\right]<\mathrm{f}(\ell) /(1-\mathrm{F}(\ell))$ if and only if $\Phi(\ell) \equiv \mathrm{h}(\ell)[1-\mathrm{F}(\ell)]-\mathrm{T}_{\mathrm{F}}+\int_{0}^{\ell} \mathrm{h}(\mathrm{t}) \mathrm{f}(\mathrm{t}) \mathrm{dt}<$ 0 . Observe that $\Phi(0)=-\mathrm{T}_{\mathrm{F}}$ and $\Phi(1)=0$. Differentiation yields $\Phi^{\prime}(\ell)=\mathrm{h}^{\prime}(\ell)[1-\mathrm{F}(\ell)]>0$. Thus $\Phi(\ell)<0$ for all $\ell \in[0,1)$. QED. 
We handle multiple optima in the same manner as discussed in Section 4 and label the PBLD marginal type that maximizes $Z(\ell ; G)$ as $\ell^{*}$. Since the (new) distribution $G(\ell)$ satisfies these two properties, the analysis of Sections 4 and 5 follows directly, subject to the substitution of $\ell$ (and $\ell^{*}$ ) for $\alpha\left(\right.$ and $\left.\alpha^{*}\right)$. 


\section{References}

Bagnoli, Mark and Ted Bergstrom. 2005. "Log-Concave Probability and its Applications," Economic Theory, 26, 445-469.

Bebchuk, Lucian A. 1984. "Litigation and Settlement Under Imperfect Information," RAND Journal of Economics 15, 404-415.

Che, Yeon-Koo. 1996. "Equilibrium Formation of Class Action Suits," Journal of Public Economics 62, 339-61.

Che, Yeon-Koo. 2002. "The Economics of Collective Negotiation in Pretrial Bargaining," International Economic Review 43, 549-75.

Dana, James D. 2001. "Competition in Price and Availability When Availability is Unobservable," RAND Journal of Economics 32, 497-513.

Daughety, Andrew F. 2000. "Settlement," in Encyclopedia of Law and Economics, Vol. V, Edited by B. Bouckaert and G. DeGeest. New York: Edward Elgar Publishing Co., 95-158.

Daughety, Andrew F. and Jennifer F. Reinganum. 2000a. “Appealing Judgments,” RAND Journal of Economics 31, 502-525.

Daughety, Andrew F. and Jennifer F. Reinganum. 2000b. "On the Economics of Trials: Adversarial Process, Evidence and Equilibrium Bias," Journal of Law, Economics, and Organization 16, 365-394.

Daughety, Andrew F. and Jennifer F. Reinganum. 2005. "Economic Theories of Settlement Bargaining," Annual Review of Law and Social Sciences 1, 35-59.

Deneckere, Raymond and James Peck. 1995. "Competition Over price and Service Rate When Demand is Stochastic: a Strategic Analysis," RAND Journal of Economics 26, 148-162.

Ginzburg, Harold M. 1986. "Use and Misuse of Epidemiologic Data in the Courtroom: Defining the Limits of Inferential and Particularistic Evidence in Mass Tort Litigation," American Journal of Law and Medicine 12, 423-439.

Goldberg, John C. P., Anthony J. Sebok, and Benjamin C. Zipursky. 2004. Tort Law Responsibilities and Redress. NY: Aspen Publishers.

Green, Michael D., D. Michal Freedman and Leon Gordis. 2000. "Reference Guide on Epidemiology," in Reference Manual on Scientific Evidence, Second Edition. Federal Judicial Center, Washington, D.C. 
Hay, Bruce L. and Kathryn E. Spier. 1998. "Settlement of Litigation," in The New Palgrave Dictionary of Economics and the Law (Vol. 3), Ed. by P. Newman. New York: Stockton Press, 442-51.

Investigative Staff of the Boston Globe. 2002. Betrayal - The Crisis in the Catholic Church. Boston: Little, Brown and Company.

Mas-Colell, Andreu, Michael D. Whinston and Jerry R. Green. 1995. Microeconomic Theory. New York: Oxford University Press.

Posner, Richard A. 1990. Cardozo - A Study in Reputation. Chicago: University of Chicago Press.

Reference Manual on Scientific Evidence, Second Edition. 2000. Federal Judicial Center, Washington, D.C.

Reinganum, Jennifer F. and Louis L. Wilde. 1986. "Settlement, Litigation and the Allocation of Litigation Costs," RAND Journal of Economics 17, 557-566.

Shavell, Steven. 1987. Economic Analysis of Accident Law. Cambridge, MA: Harvard University Press.

Spier, Kathryn. forthcoming. "Litigation," in The Handbook of Law and Economics Vol. 1, Ed. by A. M. Polinsky and S. Shavell. Amsterdam: Elsevier Science Publishers B.V.

$\underline{\text { Cases }}$

In re An Arbitration Between Polemis and Another and Furness, Withy \& Co. Ltd., 3 K.B. 560 (1921).

Jarvis v Ford Motor Co., 283 F.3d 33 ( $2^{\text {nd }}$ Cir., 2002).

Manko v. United States, 636 F. Supp. 1419 (WD MO, 1986).

Palsgraf v. Long Island Railroad Co., 248 N.Y. 339 (1928).

Schwab v. Philip Morris, 449 F. Supp. 2d 992 (ED NY 2006).

Shoshone Coca-Cola Bottling Co. v. Dolinski, 82 Nev. 439 (1966).

Summers v. Tice, et. al. 33 Cal. 2d 80 (1948).

U. S. v Carroll Towing Co, 159 F.2d 169 (2 $2^{\text {nd }}$ Cir., 1947). 